\title{
Citation rates for experimental psychology articles published between 1950 and 2004: Top-cited articles in behavioral cognitive psychology
}

\author{
Kit W. Cho • Chi-Shing Tse • James H. Neely
}

Published online: 23 May 2012

(C) Psychonomic Society, Inc. 2012

\begin{abstract}
From citation rates for over 85,000 articles published between 1950 and 2004 in 56 psychology journals, we identified a total of 500 behavioral cognitive psychology articles that ranked in the top $0.6 \%$ in each half-decade, in terms of their mean citations per year using the Web of Science. Thirty nine of these articles were produced by 78 authors who authored three or more of them, and more than half were published by only five journals. The mean number of cites per year and the total number of citations necessary for an article to achieve various percentile rankings are reported for each journal. The mean number of citations necessary for an article published within each half-decade to rank at any given percentile has steadily increased from 1950 to 2004 . Of the articles that we surveyed, $11 \%$ had zero total citations, and $35 \%$ received fewer than four total citations. Citations for post-1994 articles ranking in the 50th-75th and 90th-95th percentiles have generally continued to grow across each of their 3-year postpublication bins. For pre-1995 articles ranking in the 50th-75th and 90th95th percentiles, citations peaked in the 4- to 6- or 7- to 9year postpublication bins and decreased linearly thereafter, until asymptoting. In contrast, for the top-500 articles, (a) for pre-1980 articles, citations grew and peaked 10-18year postpublication bins, and after a slight decrease
\end{abstract}

K. W. Cho $(\bowtie) \cdot J$. H. Neely

Department of Psychology, SS 369, University at Albany,

State University of New York,

1400 Washington Avenue,

Albany, NY 12222, USA

e-mail: kitwcho@gmail.com

C.-S. Tse

Chinese University of Hong Kong,

Shatin, Hong Kong, China began to linearly increase again; (b) for post-1979 articles, citations have continually increased across years in a nearly linear fashion. We also report changes in topics covered by the top-cited articles over the decades.

Keywords Citations · Cognitive psychology · Impact factor

\section{Introduction}

The number of citations that academic articles receive has become a well-accepted, objective measure for evaluating the impact (and likely the quality) of journals (Garfield, 1972), researchers, departments, programs, or institutions (Nosek et al., 2010; Rushton, 1984). A very high citation rate for a published article indicates that the research it reports has had a major impact in guiding the research reported in other articles in that field. Hence, an academic institution or research unit that has published many highly cited articles is thought to provide an environment in which important, high-impact research can be conducted, making that institution a more desirable location for other scientists or prospective students looking to advance their careers. For a journal, highly cited articles directly affect the journal's impact factor, which can influence journal submissions, because researchers strive to publish their articles in the most prestigious, and hence widely read, journals. As for individual researchers, total citation counts are correlated with eminence in one's field, as measured by their ability to predict future Nobel laureates (Garfield \& WelljamsDorof, 1992) and attainment of other scientific awards (Myers, 1970). Moreover, the citation rate for each of an individual researcher's articles is a key component in determining that researcher's Hirsch index (h-index), which is the 
number of that researcher's published articles that have received at least $h$ citations each (Hirsch, 2005). (For example, an h-index of 5 indicates that the researcher has five articles, each of which has accrued at least five citations.) Despite the limitations of the h-index (see Krampen, Becker, Wahner, \& Montada, 2007), at academic institutions emphasizing research, it is currently one of the most widely used measures (along with grant dollars received) for determining whether a candidate should be hired, tenured, or promoted, because it is a composite measure of both quantitative research output (i.e., the number of articles one has produced) and the impact that those articles have had on guiding the research of others.

Another way that citations can be used is to determine which individual publications have had a major impact on guiding the research of others in that research area. For cognitive psychology, White (1983) identified 50 prominent publications (journal articles and books) indexed in the 1979-1982 volumes of the Social Sciences Citation Index (SSCI) that (a) had averaged more than 20 citations per year in the 1971-1982 SSCI and (b) had at least five citations per year in any one of the eight major journals he surveyed. Although White provided a reasonably good reference for prominent cognitive psychology publications at that time, it was necessarily quite limited in its scope, due to citation counts not yet being available in electronic databases. In a follow-up to White's study, Standing (2009) examined citation trends across the years for 26 of the 50 publications that White identified. Standing found that citations increased for the first 5 years after an article's publication, but then monotonically declined, a trend that he noted was also evident in the physical sciences (de Solla Price, 1986). However, one should be cautious in accepting Standing's conclusion. Because his small sample size included both textbooks and journal articles, it may be that the inverted$\mathrm{U}$ trend holds true only for textbooks or only for journal articles. Also, he counted citations only from 1971-1993, and as we show here (see Table 1 below), 14 journals that publish a large number of articles on cognitive psychology started in 1990 or later. The greater opportunity for citations in these new journals could have offset the downturn that Standing reported.

Using an electronic database that allows for a much more thorough and comprehensive analysis of a much larger sample of articles and journals, the present study updates and extends the work of White (1983) and Standing (2009). We focused on journals that mostly publish articles relevant to behavioral measures of cognition in brain-intact humans older than 5 years of age and with no diagnosis of a psychological disorder. (For brevity's sake, we will hereafter use the shorthand term "cognitive" articles in referring to articles that meet these criteria.) In particular, our goals were to identify (1) the mean number of cites per year that such articles receive, ${ }^{1}(2)$ the mean and total number of citations such articles need in order to achieve various percentile rankings relative to all surveyed published articles ${ }^{2}$ in (a) all years or (b) the same half-decade; (3) the citation trends across 3-year postpublication bins; and (4) 500 (an arbitrarily chosen number) very highly cited "cognitive" articles that were published between 1950 and 2004. We then did a more detailed analysis of these top-500 articles, including reporting (a) the journals in which they were published, (b) the distribution of the number of researchers who were authors on three or more top-500 articles, (c) how changes in citation patterns for the top-500 articles compare to those for lesser-cited articles, and (d) how the research areas represented by the top- 500 articles have changed across the years.

Our top-500 list is based on mean citations per year rather than on total citations, so as not to give an unfair advantage to older articles that would have had additional years to accumulate citations. However, ranking an article on the basis of mean citations per year without taking its year of publication into account has its limitations. Because the number of journals (and of articles published) increased rather dramatically in the late 1960s (see Table 2 below) and has steadily increased since then, more recently published articles would have many more opportunities to be cited in the peak years closely following their publication and to have less time to drop off in later years (if the temporal trend reported by Standing, 2009, holds for our much larger sample). This would give more recent articles an unfair advantage in achieving higher mean citations per year, thereby resulting in their being overrepresented in our top-500 list. To address this concern, we used a year-of-publication cohort analysis that segregated articles into one of 11 five-year bins, with articles in the first bin having 1950-1954 publication dates, and the last bin having 2000-2004 publication dates. We stopped at 2004 so that all articles would have citations from at least two 3-year postpublication bins.

\section{Method}

Procedure

From the psychology and language categories of the 2008 volume of Journal Citation Reports, we selected as potential candidates for inclusion in our sample all journals that we

\footnotetext{
${ }^{1}$ Although one might question whether the median is a more suitable measure than the mean, we used the mean because it is much more closely tied to the number of total citations, which is used to compute both a researcher's $h$-index and a journal's impact factor. Nonetheless, for some of the analyses that we report, we consider both means and medians.

${ }^{2}$ Total citations can be informative because an article that has had a moderate number of citations over a long period of time can also be considered to have had a significant impact.
} 


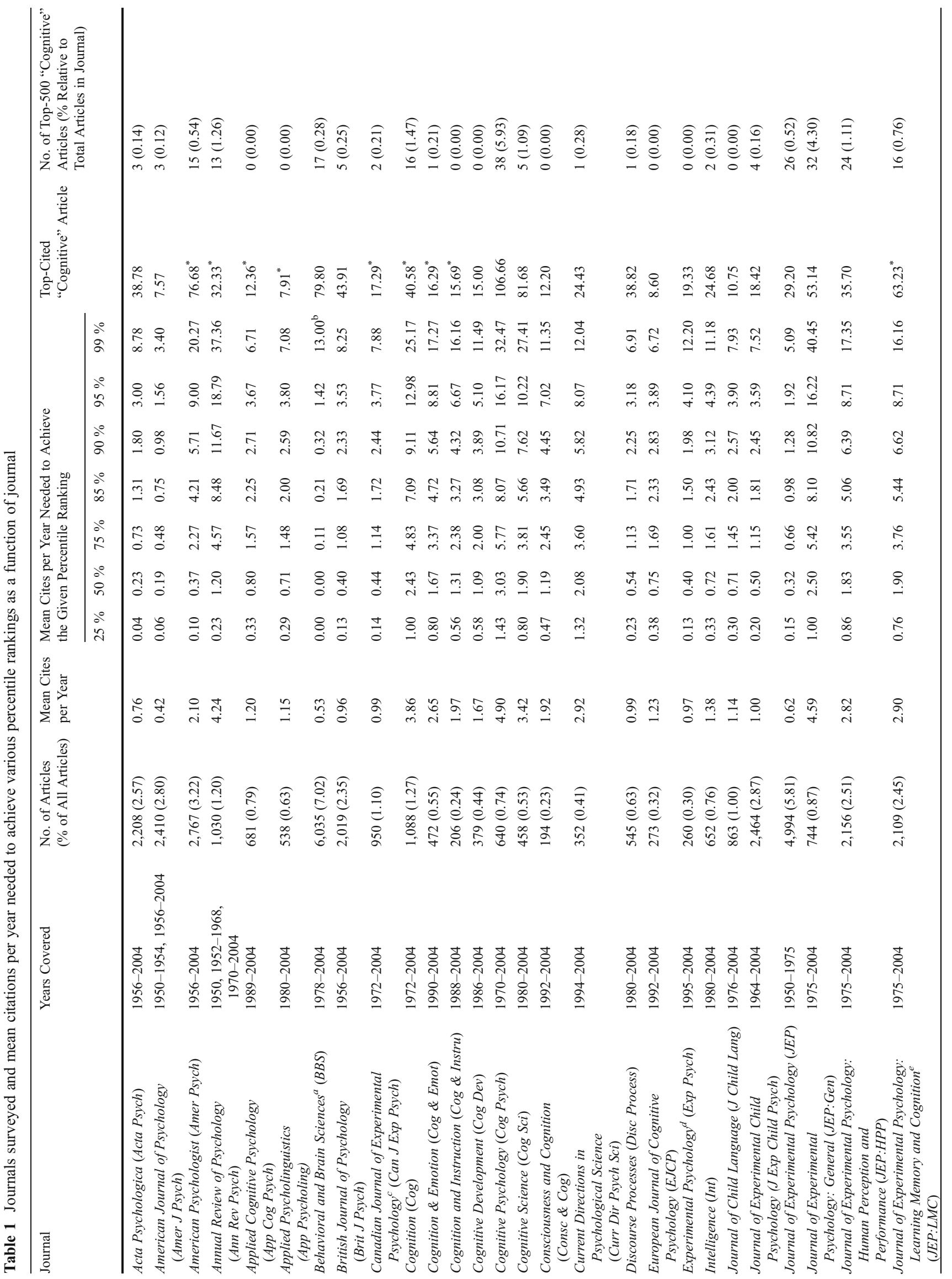




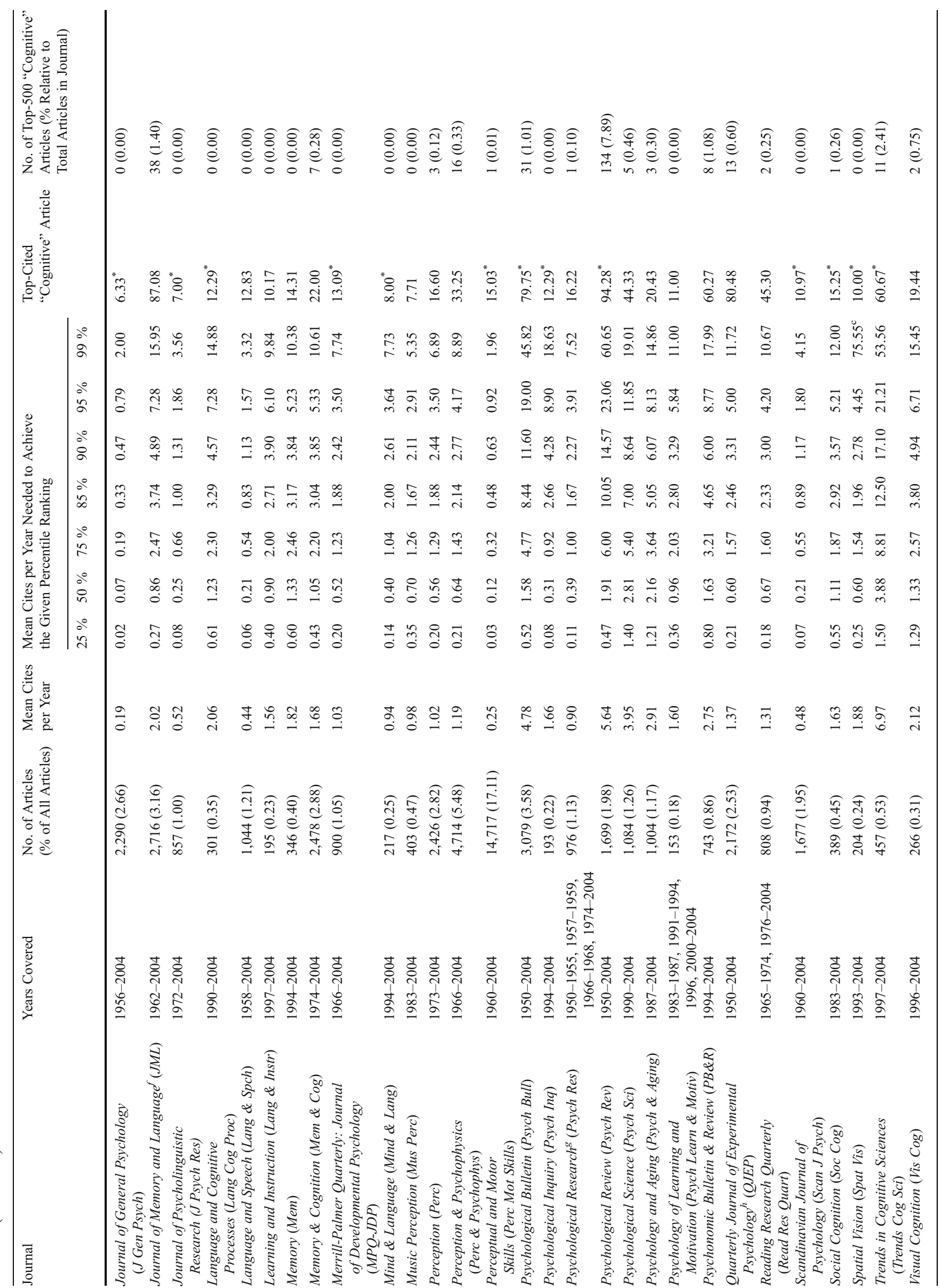




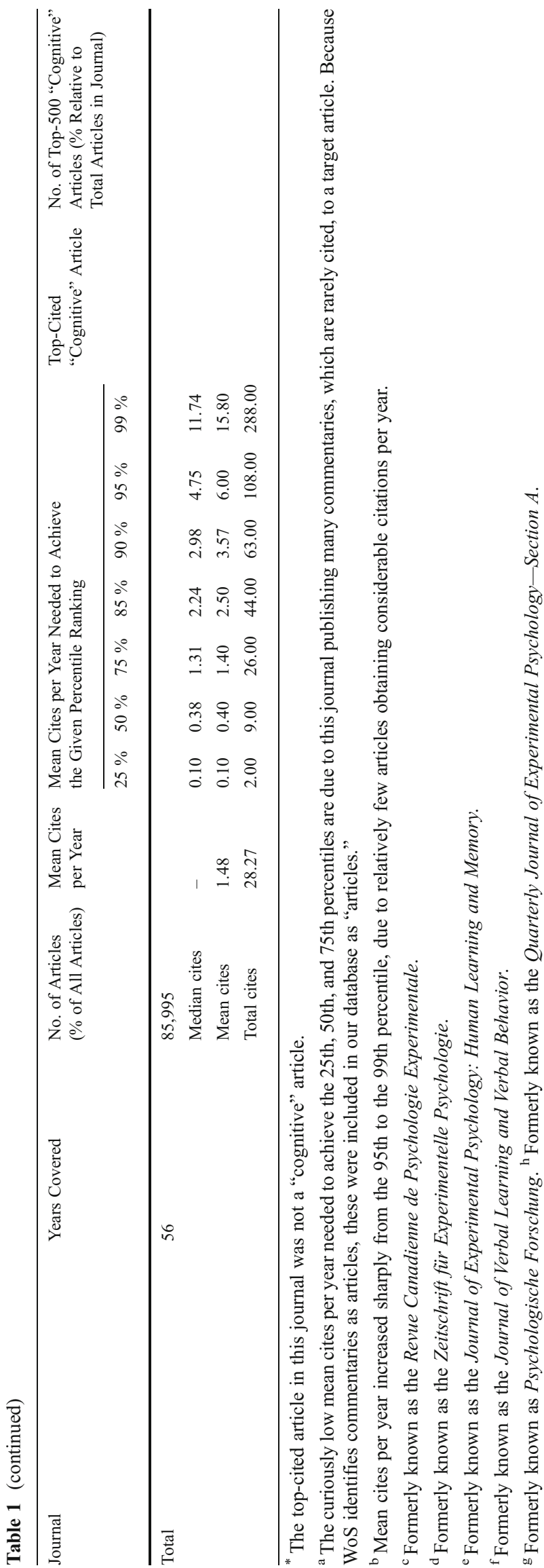

believed publish a substantial number of peer-reviewed "cognitive" articles. Because it would not be feasible to sort through thousands of articles to determine whether each article met our criteria for being included in our top-500 list, we excluded journals (e.g., International Journal of Psychology) for which fewer than $40 \%$ (an arbitrary number selected by the present authors) of their total articles are "cognitive" articles. (For journals that we were uncertain met the $40 \%$ criteria, we reviewed the content of all of the articles published in two or three randomly selected issues that were published at least 3 years apart.) We also excluded journals that primarily publish articles that (a) employ neuroimaging or electrophysiology techniques to obtain their data (e.g., Journal of Cognitive Neuroscience), (b) are not written in English (e.g., Psicologica), or (c) were not subject to even nominal peer review (e.g., Bulletin of the Psychonomic Society). Two journals, Journal of Research in Reading and Thinking \& Reasoning, that met the above criteria were nonetheless excluded because the electronic version of the Web of Science (WoS) that we had available only included 2 years of data from each of these journals. Although fewer than $40 \%$ of the articles published in some journals that publish review articles on psychological research (e.g., Psychological Bulletin and Annual Review of Psychology) are "cognitive" articles, these journals were included because many of the integrative reviews they publish have had a significant impact in the field of cognitive psychology. The 56 journals making our final list are provided in Table 1. (As indicated there, the data from renamed journals were combined - e.g., the data for the Journal of Verbal Learning and Verbal Behavior were combined with the data for the Journal of Memory and Language.)

We used the electronic 4.10 version of WoS, which includes the Science Citation Index and SSCI, to search for articles and calculate the number of citations that they received in each year since their publication. WoS is a tool well regarded by researchers, particularly social scientists, because of its comprehensiveness. As of 2011, the database consisted of 2,474 social sciences journals across 50 disciplines (Thomson Reuters, n.d.-c). The citations for each article are from all journals and book chapters indexed by WoS, though citations coming from chapters are infrequent, because the data from chapters are very limited. Although the Scopus and Google Scholar databases also provide citation counts for an article, they are less well suited to our study than is WoS. Scopus includes references only back to 1996, and Google Scholar does not separate by year the number of citations that an article has received, making the task of obtaining the data necessary for evaluating the changes in citation rates over years extremely difficult to extract. (However, it should also be noted that Google Scholar is more comprehensive than WoS, in that it includes more publications, especially books and chapters, as well as 
Table 2 Mean citations per year needed to achieve various percentile rankings as a function of year of publication

\begin{tabular}{|c|c|c|c|c|c|c|c|c|c|c|c|}
\hline \multirow[b]{2}{*}{$\begin{array}{l}\text { Year of } \\
\text { Publication }\end{array}$} & \multirow[b]{2}{*}{$\begin{array}{l}\text { Number } \\
\text { of Articles }\end{array}$} & \multirow[b]{2}{*}{$\begin{array}{l}\text { Number of } \\
\text { Top-500 } \\
\text { "Cognitive" } \\
\text { Articles }\end{array}$} & \multirow[b]{2}{*}{$\begin{array}{l}\text { Mean } \\
\text { Cites } \\
\text { per Year }\end{array}$} & \multicolumn{7}{|c|}{$\begin{array}{l}\text { Mean Cites per Year Needed to Achieve the Given } \\
\text { Percentile Ranking }\end{array}$} & \multirow[b]{2}{*}{$\begin{array}{l}\text { Range of Mean Cites } \\
\text { per Year for Top-Cited } \\
\text { "Cognitive" Articles }\end{array}$} \\
\hline & & & & $25 \%$ & $50 \%$ & $75 \%$ & $85 \%$ & $90 \%$ & $95 \%$ & $99 \%$ & \\
\hline $1950-54$ & 1,500 & 9 & 0.58 & 0.07 & 0.22 & 0.52 & 0.81 & 1.14 & 2.03 & 7.34 & $7.98-29.20^{*}$ \\
\hline $1955-59$ & 2,403 & 14 & 0.70 & 0.06 & 0.20 & 0.54 & 0.90 & 1.32 & 2.35 & 7.55 & $6.96-92.36^{*}$ \\
\hline $1960-64$ & 4,081 & 24 & 0.53 & 0.04 & 0.18 & 0.52 & 0.87 & 1.23 & 2.02 & 5.51 & $5.04-18.76^{*}$ \\
\hline $1965-69$ & 7,486 & 43 & 0.54 & 0.05 & 0.18 & 0.48 & 0.78 & 1.13 & 1.88 & 5.70 & $5.73-38.78^{*}$ \\
\hline $1970-74$ & 8,870 & 52 & 0.70 & 0.06 & 0.22 & 0.60 & 1.05 & 1.50 & 2.70 & 7.71 & $7.23-87.08$ \\
\hline $1975-79$ & 9,156 & 53 & 0.94 & 0.03 & 0.22 & 0.73 & 1.33 & 2.00 & 3.67 & 9.56 & $9.90-94.28^{*}$ \\
\hline $1980-84$ & 9,419 & 55 & 1.25 & 0.07 & 0.29 & 1.07 & 1.96 & 2.92 & 5.03 & 15.00 & $13.83-106.66^{*}$ \\
\hline $1985-89$ & 9,538 & 55 & 1.62 & 0.09 & 0.41 & 1.46 & 2.65 & 3.83 & 6.45 & 18.16 & $16.95-75.91^{*}$ \\
\hline 1990-94 & 10,550 & 61 & 1.97 & 0.16 & 0.65 & 2.00 & 3.43 & 5.00 & 8.02 & 17.16 & $15.27-81.68^{*}$ \\
\hline 1995-99 & 11,196 & 65 & 2.26 & 0.30 & 0.93 & 2.50 & 3.92 & 5.40 & 8.45 & 19.09 & $16.00-79.80^{*}$ \\
\hline $2000-04$ & 11,796 & 69 & 2.60 & 0.44 & 1.29 & 3.00 & 4.43 & 5.86 & 9.13 & 21.56 & $14.83-72.75^{*}$ \\
\hline \multirow[t]{2}{*}{ Total } & 85,995 & 500 & 1.48 & 0.10 & 0.40 & 1.40 & 2.50 & 3.57 & 6.00 & 15.80 & \\
\hline & & & Median & 0.00 & 0.27 & 1.14 & 2.09 & 3.25 & 5.36 & 14.22 & \\
\hline
\end{tabular}

* The citation rate provided here for the highest cited cognitive article in the designated half decade was exceeded by the citation rate(s) of one or more noncognitive articles that were published during that same half decade by the journals listed in Table 1.

citations from nonacademic sources such as newspapers and websites.)

Separate searches were conducted for each of the journals to find all articles (not just "cognitive" articles) published in that journal between 1950 and 2004. For some journals, WoS did not have a complete record of all of their issues. (We address this gap in the Discussion section.) In our WoS search, each journal search was refined by restricting the results to "Articles" and "Review" using the "Document Types" filter. The "Create Citation Report" feature was used to obtain the total number of citations each article received in each year from its publication through 2008, and the data were then exported, the maximum-permitted 500 articles at a time, into Microsoft Excel for further processing. Because this search resulted in a rather large number of duplicate entries in the database, the "Remove Duplicates" feature provided in Microsoft Excel was used. An entry was classified as a duplicate if another article had the same (a) title and (b) author(s) and was published in the same (c) journal and (d) year.

\section{Results}

Table 1 shows the exact years for which we were able to retrieve data for each of the 56 journals from WoS. As is shown there, our database contained a total of 85,995 articles before we culled the top-cited articles to identify those that met our criteria for inclusion as a "cognitive" article. Table 1 also shows the mean numbers of citations per year" that an article (noncognitive as well as "cognitive" $)^{4}$ would need in order to achieve a percentile ranking of $25,50,75,85,90,95$, or 99 in each journal. (It is important to note that the citation counts come from all journals covered by WoS, not just the 56 journals shown in Table 1.) The penultimate column gives the number of citations received per year by the most highly cited "cognitive" article in each journal across all of its covered years of publication. (For some of the journals, the most highly cited article was not a "cognitive" article.) The last three rows of Table 1 give the percentile data in median and mean cites per year and total cites, respectively, when the data across all journals are considered as having come from a single source.

As is shown in Table 1, the number of cites per year that an article receives is highly variable across journals. An article published in Trends in Cognitive Sciences received an average of 6.79 citations per year, whereas an article published in Journal of General Psychology received an

\footnotetext{
${ }^{3}$ The year in which the article was published was always counted as a full year in the computation of mean cites per year.

${ }^{4}$ We computed the percentile rankings for all articles rather than for only cognitive psychology articles because it would be impractical to examine over 85,000 articles so as to cull out all articles that did not meet our criteria for inclusion as a "cognitive" article.
} 
average of only 0.19 citations per year. An article only needed to average less than half a citation per year to achieve a percentile ranking of $50 \%$ across all journals. This finding is consistent with Harzing's (2010) conclusion that "The average article in the social sciences and humanities is cited less than once a year" (p. 6). (The Harzing data are based on citation counts from Google Scholar rather than WoS.) The variability across journals in the mean cites per year that an article would need to achieve a percentile ranking of $50 \%$ within each journal is much less than that needed to achieve the percentile ranking of $99 \%$. When the data are aggregated across all journals, the mean number of citations per year that an article would need to achieve a specific percentile ranking increases gradually up to the 95 th percentile. However, in order for an article to achieve a percentile ranking of $99 \%$, it needs approximately ten more citations per year than (or almost thrice as many citations as) an article at the 95th percentile. In contrast, an article at the 90th percentile needs only two additional citations per year in order to achieve a percentile ranking of $95 \%{ }^{5}$ This indicates an extreme positive skew in the frequency distribution of mean cites per year.

Examination of the total citation data reveals that $11 \%$ of all surveyed articles received zero citations, and $35 \%$ received four or fewer total citations. Thus, a large number of articles are rarely cited. As noted earlier, total citations influence the h-index, a commonly used measure of a researcher's productivity and impact. Our data also show the difficulty of achieving an h-index of 26 , which means that one would need to have published 26 articles with 26 or more total citations, ranking them in the top $25 \%$ of all of our surveyed articles.

To examine how mean citations per year have changed as a function of an article's publication date, we segregated all 85,995 articles into one of 11 five-year bins, with articles in the first bin having 1950-1954 publication dates, and the last bin having 2000-2004 publication dates. For each of these "era" bins, Table 2 displays the data corresponding to the data provided for each journal in Table 1. The mean number of citations per year as a function of era shows a clear, positive linear trend (with the mean citations per year of an article published in the 1950-1954 and 2000-2004 eras being 0.58 and 2.60 , respectively). This is not surprising, as the numbers of journals and articles (second column of Table 2) have dramatically increased over the years,

\footnotetext{
${ }^{5}$ The majority of articles in some journals, such as Spatial Vision and Behavioral and Brain Sciences, are not cited often, but a few articles from those journals are highly cited, which leads to an immense increase in the mean citations per year needed to achieve the 99th percentile ranking. For Behavioral and Brain Sciences, this is due to the fact that it publishes a few integrative target articles (highly cited) and a large number of brief comments (with very low citation rates) on those target articles.
}

thereby providing many additional opportunities for articles to be cited in more recent years. This supports the need to evaluate mean cites per year by eras. In Table 2's third column, the number of top-ranked articles to be included in each bin was adjusted for the number of total articles in that bin relative to the total number of articles across all years in the database. This adjustment was made to ensure that the bottom-ranked of the top-cited articles within all bins would have the same percentile rank within their respective bins. (The two values in the last column of Table 2 are the mean numbers of citations of the lowest- and highest-ranked top-500 "cognitive" articles in that bin.) For example, in the 1950-1954 bin there are 1,500 articles, representing $1.7 \%$ of the 85,995 total articles in the database. Hence, the nine most-cited behavioral cognitive articles (1.7\% of 500) are reported for the 1950-1954 cohort, with these nine articles ranking in the top $0.6 \%$ (i.e., 9/1,500) for that cohort. For the 1970-1974 cohort, 52 articles are reported (i.e., $[8,870 / 85,995] \times 500$ ), with these 52 articles ranking in the top $0.6 \%$ (i.e., $52 / 8,870$ ) for that cohort.

To obtain our final top-500 list, after sorting the articles within each era bin in descending order of mean citations per year, we started at the top and carefully examined each article and removed those that did not meet our inclusion criteria for "cognitive" articles. ${ }^{6}$ In addition, we excluded articles that published stimulus norms (e.g., Battig \& Montague, 1969), tutorials for software (e.g., Pelli, 1997), general statistical articles (e.g., Clark, 1973; Ratcliff, 1979), or computer modeling articles (almost all of which were published in Cognitive Science) that focused on creating computer models and evaluating what they could do, but in which human performance was not considered or was mentioned only in passing (e.g., Gentner, 1983). The articles in each era bin were culled until we reached the number needed in that bin so as to obtain our top-500 list. The resulting 500 articles across all bins are reported in Appendix A. The data are presented in ascending order of era bins and in descending order within each bin, based on mean cites per year.

In our top-500 list, 27 of the 56 journals (48\%) had zero articles or only one article represented (see the last column of Table 1), representing only $1.2 \%$ of the top-500 articles. In contrast, $54.6 \%$ (273) of our top-500 articles were published in only five journals: Psychological Review, Cognitive Psychology, Journal of Memory and Language (which includes the Journal of Verbal Learning and Verbal

\footnotetext{
${ }^{6}$ Our list includes one article in which the researchers tested a group of subjects with parietal lesions (Egly, Driver, \& Rafal, 1994). This article was included because normals were also tested, creating a new paradigm that has been extensively used with normals to test general theories of visual attention, and because over $60 \%$ of the articles that have cited it have themselves been "cognitive" articles.
} 
Behavior), Psychological Bulletin, and Journal of Experimental Psychology: General. In terms of the absolute number of articles making our top 500, Psychological Review ranked number one, with 134 articles, representing $7.89 \%$ of the total articles published in the journal between 1950 and 2004 . Because this is $26.8 \%$ of our top-500 list and is much, much higher than the $1.98 \%$ of the total articles that it published within the database we created, this makes Psychological Review by far the most overrepresented journal in our top-500 list. The journal with the second highest percentage of its articles making our top-500 list was $C o g$ nitive Psychology, at $5.93 \%$, which is much higher than the
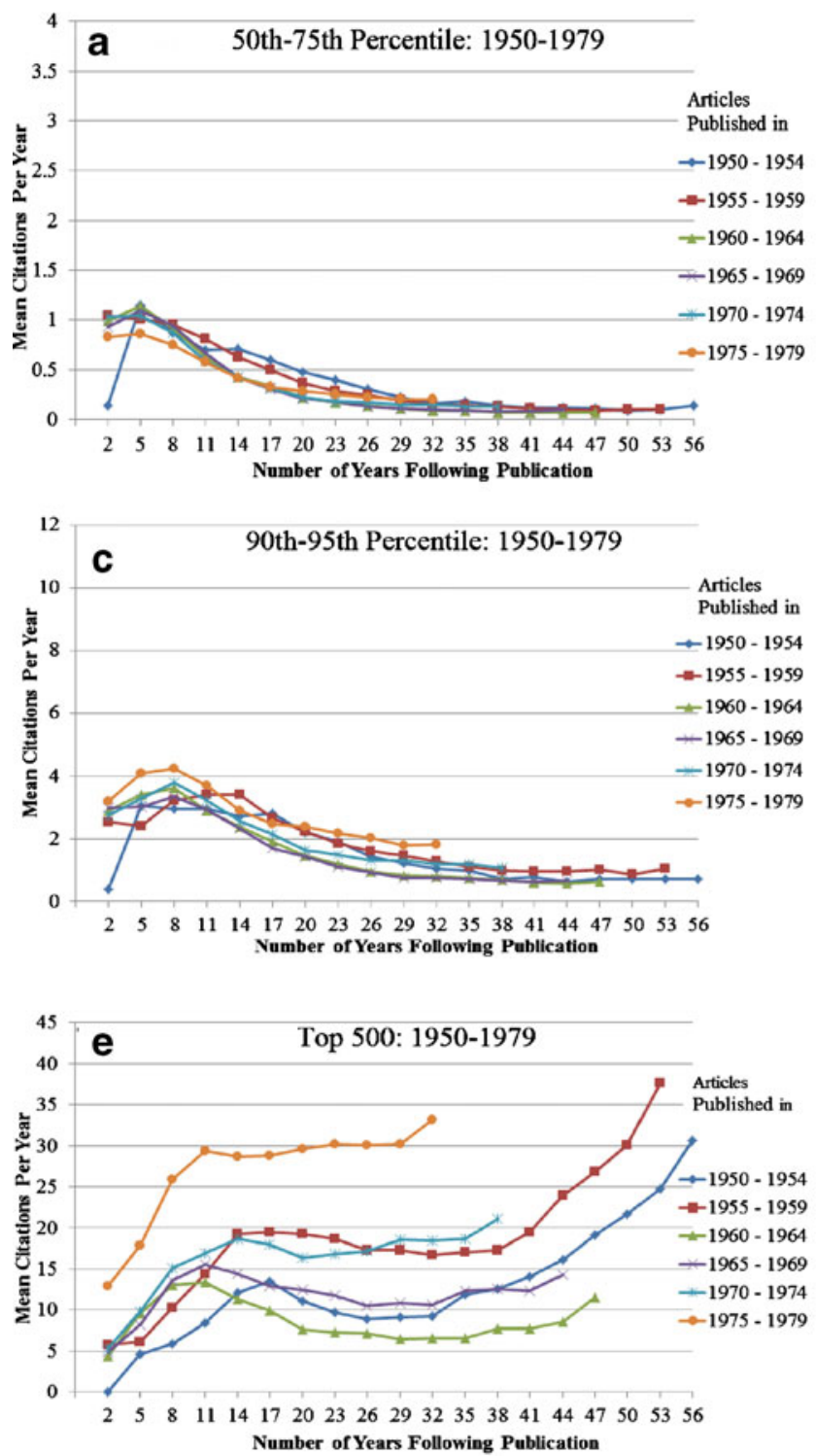

Fig. 1 Mean citations per year following publication (a) for articles ranking in the 50th-75th percentiles of articles published between 1950 and 1979; (b) for articles in the same percentile range published between 1980 and 2004; (c) for articles ranking in the 90th-95th percentiles of articles published between 1950 and 1979; (d) for articles in the same percentile range published between 1980 and 2004; (e) for articles ranking
$0.74 \%$ of the total articles in our database that it published between 1970 (its first year of publication) and 2004. Clearly, the most highly cited articles are overrepresented in only a few journals.

The three rows of panels in Fig. 1 show the mean citations per year that articles published in a specific era received as a function of the number of years after their publication. Because articles with percentile ranks below $50 \%$ showed a floor effect, Figs. $1 \mathrm{a}-\mathrm{b}, \mathrm{c}-\mathrm{d}$, and $1 \mathrm{e}-1 \mathrm{f}$ display the mean citations per year for articles having rankings in $(\mathrm{a}-\mathrm{b})$ the 50 th- 75 th percentiles and $(\mathrm{c}-\mathrm{d})$ the 90th95th percentiles of all articles (including noncognitive
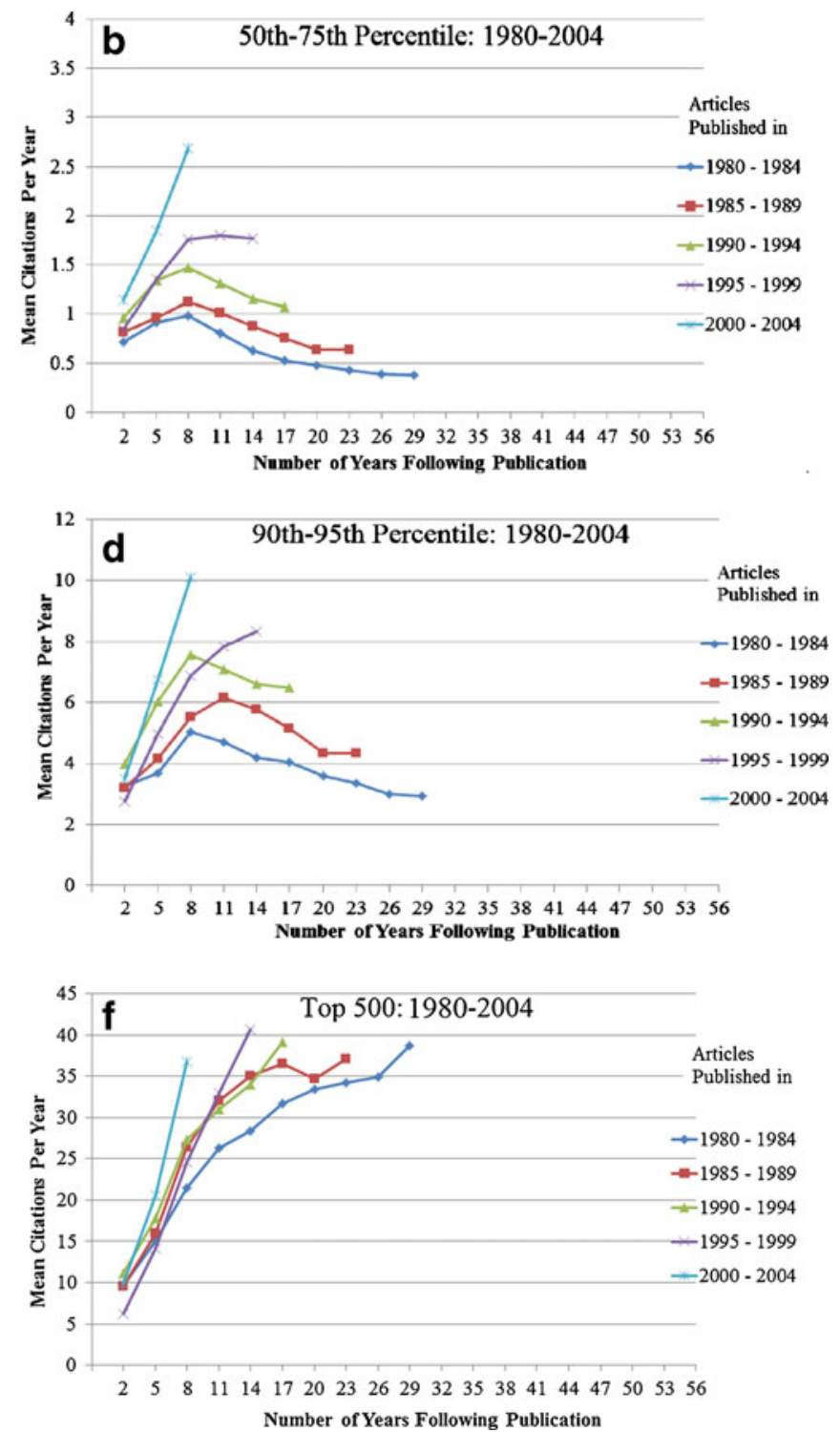

in the top-500 list published between 1950 and1979; (f) for articles in the top-500 list published between 1980 and 2004. Because the Web of Science does not separate citation data by individual years for the years 1950-1954, the data points for the first 3 years postpublication for articles published in 1950 and 1951 are for 5 and 4 years, respectively 
articles), as well as for (e-f) our top-500 "cognitive" articles, which had a percentile ranking $\geq 99.4 \%$. For the two panels within each row, the left panel shows the data for each of the six 5-year eras spanning 1950-1979, and the right panel shows the data for each of the five 5-year eras spanning 1980-2004.

As can be seen in Fig. 1, citations for post-1994 articles ranking in the 50th-75th and 90th-95th percentiles have generally continued to grow across each of their 3-year postpublication bins. This is likely because they have not been published long enough to reach their peaks. (The one exception to this general pattern is the 1995-1999 bin for articles ranking in the 50th to 75th percentiles, for which citations peaked in the 7- to 9-year postpublication bin and have remained constant thereafter.) However, for pre-1995 articles ranking in the 50th-75th and 90th-95th percentiles, citations generally peaked around 4-6 and 7-9 years after an article's publication, respectively, at which point citations thereafter decreased linearly until reaching an asymptote. In contrast, for the top-500 articles, the pre- 1980 articles' citations increased up to a peak occurring from 10-18 years postpublication, then dropped slightly for a few years, and then started to increase again up to the present, whereas for post-1979 articles, citations have linearly increased up to the present. The pre-1980 top-500 pattern is likely due to a postpeak downturn having been offset by the greater citation opportunities from the rapidly increasing number of publications during their postpeak years, and the post-1979 pattern is likely also due to this changing environment, as well as to the fact that they may not have been published long enough to reach their peaks.

A reviewer questioned whether the large upturn in cites per year for the most recent years among the articles published in the 1950-1954 and 1955-1959 eras might be due to the pronounced positive skew in citations and to our having used mean citations per year. To address this question, all data points in Fig. 1 were recomputed using the medians rather than the means contributing to those values. That is, after obtaining the mean of the 3-year citation rates for each of the $N$ articles in each bin, we examined the medians of those $N$ means rather than the means of those $N$ means (which are the data displayed in Fig. 1). The large upturn for the articles published in the 1950-1954 and 1955-1959 eras were significantly reduced when the medians were used, showing that the upturn observed for each of these two eras was produced by only a few articles that received very high citation rates in recent years. However, this difference between the mean versus the median data only occurred in the two aforementioned eras, likely because the data from those eras were based on many fewer articles than were the data for the other eras. (See Table 2.) For all of the other panels, the overall values for the means and medians were very similar. Another trend of interest for the top-500 articles is that, for post-1974 articles, the number of citations per year in their first three postpublication years increased dramatically, to more than ten citations per year, as compared to articles from all previous eras, which averaged about five citations per year.

A comparison of our data with White's (1983) data reveals that 18 of the 24 journal articles identified by White met our criteria for being a "cognitive" article. All 18 of these ranked in the top 36 of the 173 of our top-500 articles that were published between 1956 and 1978, the years covered by White. These 18 articles received 44.7 cites per year in 1979-1982 (the years analyzed by White) and 43 cites per year in 1983-2008. The mean cites per year for the remaining 155 articles from the same cohort in our top-500 list were 12.99 and 15.91 cites per year, respectively. Clearly, despite the limitations of White's procedures, which were imposed by practical considerations, the articles that he identified were indeed among the most highly cited articles published in the years that he covered, and they exhibited a "staying power" comparable to that of the other 155 articles that our more extensive search procedures captured.

Our data are contrary to Standing's (2009) data, which showed that mean citation rates for very prominent 19711976 cognitive psychology articles peaked 5-8 years following publication and then showed a gradual decrease up to 22 years postpublication. For the 59 articles from 1971 to 1976 on our top-500 list, no downturn in citations was indicated. Indeed, the highest number of mean citations (21.66) occurred in the 22nd postpublication year, and for the years beyond that, the mean citation rate of 25.68 in the 32th postpublication year was highest of all. A similar conclusion applies for the citation patterns of all the top-500 articles, not just those published between 1971 and 1976. However, as is shown in Fig. 1, Standing's conclusion regarding an inverted-U-shaped citation function does generally hold for pre-1995 articles that rank between the 90th and 95th percentiles. The one exception was the 1950-1954 articles, of which with the exception of the first post-publication bin in Fig. 1, which had relatively constant citations across the earliest years before their citations began to decline, a pattern also observed for pre-1995 articles ranking in the 50th-75th percentiles (the exception being the 1950-1954 articles, which showed Standing's inverted-U function).

Table 3 provides the distributions of the numbers of top500 articles authored or coauthored by the 78 researchers with three or more top-500 articles, as well as the numbers of articles on which they were (a) the sole author, (b) the first author, or (c) a "junior" author. The 78 researchers represented in Table 3 had a total of 67 articles on which they were the sole author, and another 127 articles on which they were the first author. Thus, only $11 \%$ of all of the authors of top-500 articles (i.e., 78 of 695) were primarily responsible for $39 \%(194 / 500)$ of those articles. Clearly, the 
Table 3 Distribution of the authors with three or more top-500 articles, the data from the supplemental HPOP search, the authorship arrangement of those articles, and their h-indices

\begin{tabular}{|c|c|c|c|c|c|c|c|c|c|c|c|c|c|}
\hline \multicolumn{6}{|c|}{ Journal Articles in Top 500 in the WoS search } & \multicolumn{7}{|c|}{ Supplemental HPOP Search } & \multirow[t]{3}{*}{ h-Index } \\
\hline \multirow{2}{*}{$\begin{array}{l}\text { Number of Top-500 } \\
\text { Articles }\end{array}$} & \multirow[t]{2}{*}{$N$} & \multicolumn{3}{|c|}{ Authorship } & \multirow[t]{2}{*}{ Total } & \multirow[t]{2}{*}{ Journal $^{\mathrm{a}}$} & \multirow[t]{2}{*}{ Book $^{b}$} & \multirow[t]{2}{*}{ Chapter } & \multicolumn{3}{|c|}{ Authorship } & \multirow[t]{2}{*}{ Total } & \\
\hline & & Sole & First & Other & & & & & Sole & First & Other & & \\
\hline $9-12$ & 3 & 6 & 13 & 13 & 32 & 23 & 2 & 10 & 5 & 16 & 14 & 35 & 83 \\
\hline $7-8$ & 4 & 6 & 7 & 18 & 31 & 2 & 1 & 7 & 1 & 5 & 4 & 10 & 61 \\
\hline 6 & 5 & 7 & 12 & 11 & 30 & 2 & 2 & 7 & 5 & 5 & 1 & 11 & 45 \\
\hline 5 & 6 & 6 & 16 & 8 & 30 & 3 & 9 & 2 & 9 & 3 & 2 & 14 & 60 \\
\hline 4 & 20 & 12 & 34 & 34 & 80 & 8 & 19 & 13 & 19 & 13 & 8 & 40 & 54 \\
\hline 3 & 40 & 30 & 45 & 45 & 120 & 12 & 27 & 32 & 43 & 20 & 8 & 71 & 49 \\
\hline Total & 78 & 67 & 127 & 129 & 323 & 50 & 60 & 71 & 82 & 62 & 37 & 181 & \\
\hline
\end{tabular}

$N$ is the number of authors having the various numbers of top-500 WoS articles. The procedure for our supplemental search is found in Appendix B. ${ }^{a}$ The Journal category includes technical reports $(n=3)$ and articles that we missed from the journals that we surveyed $(n=5)$; all other articles are from journals that we did not survey or from years that were missing in WoS. ${ }^{b}$ Includes popular books (i.e., nonacademic books), of which there were very few.

field of cognitive psychology is being guided to a large degree by a small number of researchers.

To examine possible changes across years in the research areas that were being emphasized, we categorized the general research topic(s) covered in each of our top-500 articles and then aggregated them into five eras: (1) 1950-1969 (we combined the articles originating in the 1950s with those in the 1960s because there were too few articles in the former decade; total combined $N=90)$, (2) 1970-1979 $(N=105)$, (3) 1980-1989 ( $N=110)$, (4) 1990-1999 $(N=126)$, and (5) 2000-2004 $(N=69)$. We will first consider four general categories: memory (including sensory memory, short-term memory, and episodic and semantic long-term memory), language (including reading and speech perception), attention/ perception, and thinking (which includes decision making, reasoning, and problem solving). ${ }^{7}$ The percentages of top500 articles on thinking and memory have remained relatively constant across eras; articles on language have shown an inverted-U function, peaking in the 1980s; and articles on attention/perception remained constant through the 1980s, but then showed substantial increases in the 1990s and 2000s.

As for research subcategories, the percentages of articles on information theory and psychophysics were appreciable in the 1950s and 1960s, but since then have been negligible. The percentages of top-500 articles on imagery and implicit longterm memory were noticeably higher in the 1980s than in the

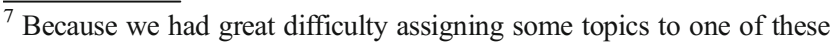
four general categories (e.g., imagery, embodied cognition, categorization, and motor skills, to name a few topics), we will not present detailed quantitative analyses, but rather will only speak in qualitative generalities and describe only those differences that were most salient to us. All statements regarding the topics covered in the various bins take into account the differing numbers of articles on our list from those bins.
}

other eras. The same general statement applies to semanticpriming, categorization, and decision-making articles, but with the 1980s-1990s being "high" points, and with the percentages of articles on categorization, implicit long-term memory, and decision making being higher than those for semantic priming and imagery. The percentage of top- 500 articles on false memory was relatively high in the 1990s but negligible in other eras. Also of note is that no articles on embodied cognition or task switching appeared until the 1990s, when they made a substantial jump, and then a much bigger jump in the 2000s. Finally, the topic of short-term memory has shown an interesting evolution: The percentage of top-500 articles related to this topic was quite high from 1950 to 1970 , then showed a precipitous drop in the 1980s, as predicted by Crowder (1982), but then showed a dramatic increase in the 1990s, and another dramatic increase in the 2000s. However, the nature of the post-1980s short-term memory research (which is called "working memory research") represented in the top-500 list is quite different from that of the pre-1980s research. The post-1980s research focuses on how individual differences in short-term memory span measured under conditions of distraction (the so-called "operations span task") are related to attentional control. The pre-1980s research mostly (but not exclusively) focused on the variables that affect memory span per se or on recency effects in immediate free-recall tests. The post-1980s increase in top-500 articles focusing on individual differences in working memory and attentional control has also occurred in language research. Finally, we note that research pertaining to aging peaked in the 1990s in the memory, language, and perception categories.

One potential caveat in interpreting the aforementioned changes in the representation of certain research areas across 
the years is that these changes are based on our top-500 list, and not on all published articles. However, if an article on research topic $\mathrm{X}$ is being cited enough to make our top-500 list, this necessarily means that a large number of articles related to that topic are being published. Hence, we are confident that the conclusions that we have drawn accurately reflect the trends in the published literature at large.

\section{Discussion}

To our knowledge, this study is by far the most comprehensive citation analysis reported on the citation rates for psychology articles in any topic area. The data that we provide can be used in a variety of ways. Administrative officials and faculty committees that do not include cognitive psychologists but are making hiring decisions or tenure and promotion decisions for cognitive psychologists can use the percentile ranks for mean citations per year and total citations per article to assess more objectively and accurately the impact of the research of the candidates whom they are considering. Both researchers and nonresearchers (e.g., journalists) can also use this information to determine objectively the percentile ranking of an article that is receiving a certain number of citations per year. Specifically, people who read an article published in one of the 56 psychology journals listed in Table 1 that receives more than five citations per year will know that this article ranks somewhere between the 90th and 95th percentiles of all articles published in those journals. Thus, the research that such an article reports has been deemed to be important by the scientific community at large and has been viewed as being credible by other researchers in the field.

Our top-500 list can also perhaps serve as a valuable reference for a novice instructor teaching an advanced cognitive psychology course, or perhaps for a more experienced instructor in a history of psychology course. Young researchers and graduate students can also benefit from these data by using them to help determine previous and current fruitful research areas, thereby allowing young researchers to make informed decisions as to whether they want to resurrect an old but popular research area or follow the current zeitgeist.

\section{Do citations measure quality?}

Does a high number of citations for an article actually indicate that it is of high quality? One might argue that the opposite could be true in a few cases: a poorly executed study might be repeatedly cited as an example of what not to do. While this is plausible, we and others (Roediger, 2006; Rushton, 1984) believe that this is highly improbable. Although an initial brief flurry of articles may critique an article that has reported a controversial phenomenon that is in fact a procedural artifact, once it has been established that the phenomenon was indeed based on flawed procedures, citations of the article reporting it would cease. Some empirical evidence also supports this belief. As cited in a report by the London School of Economics Public Policy Group (2011) that is titled Maximizing the Impacts of Your Research: A Handbook for Social Scientists, the Impact of Social Sciences Project reviewed 10,400 citations in social sciences articles and reported that only 10 of those citations were attributed to an article expressing negative commentary. These arguments notwithstanding, with respect to the quality issue, it must be acknowledged that citations directly measure only impact and are merely an indirect measure of research quality.

Although we believe that highly cited articles are indeed of high quality, this does not mean that modestly cited articles are of low quality. Flawlessly and even cleverly designed experiments that yield clean and decisive data may be only modestly cited, due to their being in a somewhat narrow research area that is being investigated by a small number of researchers. Alternatively, a seminal article that was highly cited for a decade or so after its publication may no longer be cited because it has been superseded by a more recent article that extends the seminal research or by a review article that integrates the seminal article's findings with more recent literature. In this case, the seminal article will not be cited, even though it is still having an indirect impact on research. Hence, although the total number of citations generally denotes the quality of the article, when an article is not well cited this does not necessarily imply that it is of low quality. However, for articles that have not been superseded by more recent articles, a low citation rate does indicate that the article is not having a major impact on the field in general. As always, defining the appropriate "cohort" is important. One needs to distinguish, for instance, whether a particular 1992 article on psychophysics is having a general impact (in which case the appropriate comparison group is all "cognitive" psychology articles, and the impact, as measured by citations, would be small, because psychophysics is a small field post1990) or an important impact on psychophysics research (in which case, its citation rate should be compared to those of other psychophysics articles published around the same time).

\section{Caveats in interpreting journal impact factors}

A journal's immediate impact factor is provided in the Thomson Reuters Journal Citation Reports and is calculated by dividing the total number of current year citations the source items published in that journal during the previous two years by the number of articles that were published in that journal during the previous two years (Thomson Reuters, n.d.-a). Although a journal's immediate impact factor is often taken as a measure of its quality and importance to the field, our data raise two caveats regarding the interpretation of this measure. Specifically we focus on how the proliferation of journals and articles across years and how a very few highly influential articles published in a 
journal (i.e., a positive skew) can affect a journal's immediate impact factor.

As is shown in Table 2, mean citations per year have been increasing over the years for all journals. Thus, the immediate impact factors of all journals are also increasing over time. For example, according to Journal Citation Reports (Thomson Reuters, n.d.-a), the immediate impact factors of Journal of Memory and Language in 2002, 2006, and 2010 were 2.08, 2.83 , and 4.01 , respectively. An increase in a journal's immediate impact factor over time is to be expected, according to the findings by Althouse, West, Bergstrom, and Bergstrom (2009) that the annual growth rate of psychology journals from 1995 to 2004 was $3.3 \%$. Another factor contributing to the increasing mean citations per year is the increasing length of the reference lists of articles over time (Adair \& Vohra, 2003). Thus, to determine whether an increase in a journal's immediate impact factor for year $\mathrm{Y}$ relative to year $\mathrm{X}$ is due to factors other than a proliferation of new journals, one needs to focus on the magnitude of this increase relative to other similar journals in the discipline. We believe that the best way to do this is to compute that journal's $z$ score within the distribution of immediate impact factors for all of the journals in its cohort for year $X$ and for year $Y$, and then to compare these two $z$ scores.

Our finding that there is a strong positive skew in citation data serves as another caveat for interpreting a journal's immediate impact factor. Because a journal's immediate impact factor is based on the mean of a small number of journal articles published in the previous 2 years, it can be affected to a large degree by a few highly cited articles that happened to be published in the previous 2 years. As is shown in Table 1, some journals have published a few articles that are cited much more than most of the other articles in those journals. This would inflate a journal's immediate impact factor. For example, using our data, American Psychologist's 2002 impact factor was 4.50, and its 2004 impact factor was 3.10. This finding is intriguing, considering that most journals' impact factors should increase, not decrease, over time (see Althouse et al., 2009). The reason that American Psychologist's impact factor was higher in 2002 than in 2004 is because the former impact factor included two articles published in 2000 and 2001 that received 42 and 28 citations, respectively, in 2002. However, because no article published in 2002 or 2003 received more than 14 citations in 2004, the latter impact factor was lower. (See the 2005 editorial "Not-So-Deep Impact" for a similar analysis applied to Nature.) The instability of immediate impact factors has led the Journal Citation Report to supplement the traditional 2-year impact factor with a 5-year impact factor, which ameliorates but does not eliminate the problem.

A recent article by Hegarty and Walton (2012) examined nine factors that predict an article's citation count. Of the nine factors, the number of references in an article was the strongest predictor, $\beta=.25$; the second strongest predictor was the year in which the article was published, $\beta=.23$, which is congruent with the present results showing that more recent articles receive more cites per year. Both of these predictors were better predictors of citation counts than was a journal's impact factor, $\beta=.15$. However, it should be noted that although the authors sampled a journal from each of the subdisciplines of psychology defined by the Web of Knowledge, they based their citation counts on the $P$ sycINFO database, ${ }^{8}$ and sampled a limited number of articles $(1,147)$ in a limited number of years $(1996-2005)$ from a limited number of journals (nine).

\section{Limitations of the present approach}

An obvious and important limitation of the present data is that we excluded journals and articles that employed neuroimaging and electrophysiological techniques. With the refinement of and increased availability of these methods in the past decade, it is likely that the number of such articles will increase even more dramatically over the next decade. Given that the immediate impact factors of neuroscience journals are considerably higher than those of journals that publish behavioral "cognitive" articles, the inclusion of cognitive psychology articles that use imaging and electrophysiological measures to assess the impact of "cognitive" articles, as defined here, would be misguided in the same way that including articles from all areas of cognitive psychology to assess the impact of articles within the subdiscipline of psychophysics would be misguided. Thus, we leave it to future research to use our methods for identifying the highest-impact cognitive neuroscience articles. A comparison of the citation rates and of their temporal patterns for behavioral cognitive research and cognitive neuroscience research would also be of considerable interest.

Although our analysis of "cognitive" articles is comprehensive, it is not entirely complete. We likely failed to find some "cognitive" journal articles that should be in our top-500 list because, as noted earlier, we were unable to obtain the complete record of some of the journals that we included in our sample (see Table 1). In such instances, we supplemented our WoS search using the Journal Impact analysis component of Harzing's Publish or Perish software (2007; HPOP), version 3.4.4351 (which accesses data from Google Scholar), to search for articles in those missing years that might have qualified for entry into our top-500 list. We also used HPOP data for the aforementioned excluded journals, Journal of Research in Reading and Thinking \& Reasoning. To take into account the fact that citation counts in Google Scholar are almost always greater than those obtained in WoS (and often by a considerable number; see the supplemental materials for Nosek et al., 2010), we only considered an article listed in Appendix B to have

\footnotetext{
${ }^{8}$ From the authors' anecdotal experience, the citation counts retrieved using PsychINFO are often considerably smaller than those retrieved using WoS.
} 
qualified for our "top-500" list if it received a mean citationsper-year value that was $20 \%$ higher than that of the lowestcited article in its era, shown in the last column of Table 2. (Hereafter, we will present "top-500" in quotes, as in the previous sentence, when it refers to all articles in both our original top-500 list and the supplemental articles listed in Appendix B.) Appendix B lists these 13 missed articles, which represent $2.6 \%$ of the 500 articles on our original list that were missed because of our incomplete WoS version.

Another reason why we likely missed highly cited "cognitive" articles is that we did not include high-impact journals, such as Science and Nature, that only rarely publish articles relevant to "cognitive" articles. For example, an article published in Science by Shepard and Metzler (1971), on mental rotation, and another in Nature by Luck and Vogel (1997), on visual working memory, have 65 and 37 mean citations per year, respectively, and would have made our top-500 list. Although a number of other Science and Nature articles likely would have also made our list, we did not include them because, at present, WoS does not categorize articles into subcategories. Because Science and Nature have each published more than 49,000 articles between 1950 and 2004, and most of these articles tend to be very highly cited, to create our original top-500 list it would have been impractical for us to manually cull and remove all of these irrelevant, more highly cited articles so as to find the relevant "cognitive" articles.

Another potential limitation of our method is that we did not include books or chapters in our database. Although one can access citations to some chapters or books in WoS, this can only be done by entering the names of individual authors. Clearly, it would be impractical to do this for the thousands of cognitive psychologists who published between 1950 and 2004. However, we do note that a book, Neisser's (1967) Cognitive Psychology, which arguably launched the field of behavioral cognitive psychology as it exists today, has received a mean of 131 citations per year in HPOP. Because it was impractical to include books, chapters, and journals that only infrequently publish "cognitive" articles, we supplemented our top-500 list by conducting the practically possible individual searches for each of the 78 authors in our Table 3 (i.e., researchers who authored three or more top-500 articles) using HPOP to identify articles, books, and book chapters that they had published that would have made it into our top-500 list had they been included. Once again, we used the " $20 \%$-greater" criterion described earlier. The right side of Table 3 displays the relevant data. We found that the top 78 authors produced a total of 181 highly cited journal articles, books, and chapters that were missed by our WoS search, with 50 of these being journal articles. The 50 articles came from a total of 28 different journals, with Science accounting for the highest proportion (18\%), and the American Economic Review and Quarterly Journal of Economics tying for the second-highest proportion (8\%). Thus, the WoS search missed $13.4 \%$ (i.e., 50/[50 +
323]) of the highly cited journal articles by these 78 authors. The three top authors, who produced $9.9 \%$ (i.e., 32 of 323 ) of the top-500 articles from our WoS search procedures, accounted for $46 \%$ (i.e., 23 of 50 ) of all of the additional highly cited journal articles that we identified in our supplemental search. It is also noteworthy that, whereas the WoS search missed $41 \%$ (i.e., 23 of [32+23]) of these three authors' very highly cited journal articles, it only missed from $6.1 \%$ to $9.8 \%$ of the highly cited journal articles in the remaining five frequency categories in rows 2-6 of Table 3 . This suggests that the most highly eminent cognitive psychologists publish a high percentage of their highly cited articles in journals other than mainstream cognitive psychology journals. Other notable features of the data provided by the supplemental HPOP search for the top 78 most highly cited authors were as follows. (1) Of their 500 total publications that qualify as among the most highly cited (i.e., have mean citation rates in the top $0.6 \%$ of the most highly cited articles identified in our original WoS search), $74 \%$ were journal articles, $12 \%$ were books, and $14 \%$ were book chapters. (2) Under the reasonable assumption that considerably fewer than $12 \%$ of cognitive psychologists' publications are books, this indicates that books garner many more citations than do journal articles. It is also interesting that these data seem to suggest that book chapters, which many believe have much less impact on average than do journal articles, are not underrepresented in these authors' highly cited works. (This is under the assumption that no more than $12 \%$ of these authors' total publications are book chapters.) (3) As one moves from the top row of Table 3 (authors with 9-12 top-500 articles) to the bottom row (authors with three top-500 articles), there is a monotonic decrease in the percentage of their total highly cited works that are journal articles (from $82 \%$ down to $69 \%)^{9}$ (4) For the 12 authors with 6-12 top-500 journal articles in the WoS search, $17 \%$ of the highly cited works that are not journal articles are books, and the other $83 \%$ are book chapters, whereas for the 66 authors with 3-5 top-500 journal articles in the WoS search, $54 \%$ are books and $46 \%$ are book chapters. This could be due to the high visibility of the 12 top authors leading to their being more likely to be invited to contribute chapters in edited volumes published by high prestige publishing houses.

The last column of Table 3 provides the average h-index for the authors who make up each category. Each author's hindex, which included books and chapters as well as journal articles, was obtained using HPOP after imposing the restriction of considering only articles published before 2005 . (This restriction was used so as to be consistent with our evaluating only articles published before 2005.) The average h-index for all 78 authors was 53 , and the median was 50 . It is

\footnotetext{
${ }^{9}$ The $82 \%$ value for the top three most cited authors is inflated, because eight of these publications were coauthored by two of these authors and were counted twice, once for each author.
} 
important to keep in mind that these 78 authors can be considered to be the crème de la crème of prominent cognitive psychologists, and thus that their h-indices are expected to be much higher than those of other quite prominent researchers in the field. Authors with more top-500 papers generally had higher h-indices, with the exception of authors with six top500 articles, whose h-indices were lower than those in the categories above and below them. Also, the data in the top four categories should be interpreted with caution because of their small sample sizes. At the individual-author level, there was a positive correlation between an author's h-index and the total number of the articles that the author had on the "top500 " list, $r(76)=.590, p<.001$. (As is indicated in Table 3 , the range in the number of top-cited articles was 3-12; the range in the $78 \mathrm{~h}$-indices was $19-128$. Our speculation is that had the correlation been based on researchers having three or more articles in the top $10 \%$ of most-cited articles, the correlation would have been considerably higher.)

One could argue that the fact that we did not exclude selfcitations would inflate the number of "true" citations that an article had received. While this would undoubtedly substantially affect the articles with only a few citations (most of which might be from one of the authors of the article being cited), it should have a very small effect for articles making our "top500" list. In a related vein, Endler (1977) reported that the correlation between total citations and the total citations excluding self-citations for faculty members across 35 psychology departments was a remarkable .994 . With respect to selfcitations in journals (i.e., an article published in a journal citing another article from the same journal), Thomson Reuters (n.d.b) sampled 5,876 journals across different disciplines and reported "a very weak negative correlation between Impact Factor and self-citation $\left(R^{2}=0.0368\right)$." These data indicate that the inclusion of self-citations in our study does not invalidate it. (See Wilhite \& Fong, 2012, for a recent controversy regarding journal self-citations and coercive citation practices.)

Another caveat pertains to evaluating a researcher's rather than a journal's impact. Our list of the 78 researchers having three or more articles on our "top-500" list represents (positively) deviant outliers based on an arbitrary cutoff, and hence likely misses a number of researchers who may have published a large number of articles ranking in the 95th-99.4th percentiles. However, if one wants to determine if a specific researcher who did not author one of our "top-500" articles is nevertheless having a major impact by publishing a large number of papers ranking in the top 5\%, that researcher's name can be used in an Author Impact analysis using the HPOP program (Harzing, 2007), which provides the mean cites per year received by each of that author's articles (including books and chapters). These values can then be compared to the values in Table 2 to determine how many of that person's articles rank in the top $5 \%$, although one must take into account the fact that HPOP citation counts are often considerably higher than WoS citation counts. Unlike
WoS, which only provides a researcher's h-index, HPOP also provides other measures of impact, such as the e- and g-indices (Egghe, 2006; Zhang, 2009). These measures distinguish researchers who may have produced a few very highly cited articles from those who have produced a larger number of more moderately cited articles, an aspect of a researcher's citation profile that is missed by the h-index. In this regard, we note that Nosek et al. (2010) created a database in which one can compare his or her h- and e-indices to those of 611 faculty members from various social-personality psychology Ph.D. programs who received their Ph.D.s at the same time as the person doing the query. We hope that an analogous database will be created for the subarea of cognitive psychology.

\section{Future research}

Although we have identified over 500 "cognitive" psychology articles that rank in the top $1 \%$ of the most highly cited articles published between 1950 and 2004 in 56 journals, we have not performed the analyses necessary to determine which factors are predictive of an article achieving this elite level of citation counts. As noted earlier, an analysis (though quite limited in scope) of the factors predictive of citation counts for journal articles has recently been reported by Hegarty and Walton (2012) for articles taken from various subdisciplines in psychology. What would be of interest would be a larger-scope survey that could determine whether the factors that affect citation counts differ for the different subdisciplines. A brief list of questions that might be considered would include the age and sex of the first author; whether the research was based on a dissertation (see Roediger, 2004); the number of authors, article length, and number of references; the content of the article's title or abstract; the academic "genealogy" of the authors; and the natures of the institutions at which research was conducted. Also of interest would be whether the citation rates for the top $1 \%$ of the most highly cited articles could be predicted from regression equations based on the citation rates for articles ranking $95 \%$ or below, or whether, because of the strong positive skew of the citation distribution, these top $1 \%$ are somehow qualitatively different.

\section{Conclusion}

Although not all of our findings may generalize to other areas of psychology, or even to other subdisciplines in cognitive psychology (e.g., articles that focus on the neural bases of cognition), we believe that a number of our conclusions are applicable to other areas of psychology. For example, our data showing that half of all of the articles that we sampled received less than half a citation per year are congruent with the conclusion reached by Harzing (2010), who sampled articles in the social sciences and humanities. But even if the present results 
do not generalize to other areas of psychology (which would be interesting), we believe that they provide a considerable amount of useful, interesting, and objective information regarding (a) the most-cited "cognitive" psychology journal articles, (b) the changes that have occurred in the research areas of the articles that are very highly cited, and (c) the percentile ranking that an article achieves relative to other articles published in the same era based on its mean citations per year. We thus hope that our study will encourage other researchers to conduct similar studies in their areas or disciplines, so as to assess the generalizability of the results that we have reported here.

Author Note We thank Gordon Gallup, Douglas Hintzman, and Henry L. Roediger for helpful comments.

\section{Appendix A}

The 500 articles with the highest mean citations per year, arranged in ascending order by eras, and within each era in descending order of mean cites per year

\begin{tabular}{|c|c|c|c|c|}
\hline Author(s) & Title & Journal $^{\mathrm{a}}$ & Year & Cites/Year \\
\hline \multicolumn{5}{|l|}{ 1950-1954 } \\
\hline Fitts, PM & $\begin{array}{l}\text { The information capacity of the human motor system } \\
\text { in controlling the amplitude of movement }\end{array}$ & $J E P$ & 1954 & 29.20 \\
\hline Attneave, $\mathrm{F}$ & Some informational aspects of visual perception & Psych Rev & 1954 & 17.42 \\
\hline Hick, WE & On the rate of gain of information & QJEP & 1952 & 14.32 \\
\hline Edwards, W & The theory of decision making & Psych Bull & 1954 & 13.42 \\
\hline Hyman, R & $\begin{array}{l}\text { Stimulus information as a determinant } \\
\text { of reaction time }\end{array}$ & $J E P$ & 1953 & 9.63 \\
\hline Tanner, WP; Swets, JA & A decision-making theory of visual detection & Psych Rev & 1954 & 9.31 \\
\hline Noble, CE & An analysis of meaning & Psych Rev & 1952 & 8.67 \\
\hline Wallach, H; Oconnell, DN & The kinetic depth effect & $J E P$ & 1953 & 8.27 \\
\hline Fitts, PM; Seeger, CM & $\begin{array}{l}\text { S-R compatibility: Spatial characteristics of stimulus } \\
\text { and response codes }\end{array}$ & $J E P$ & 1953 & 7.98 \\
\hline \multicolumn{5}{|l|}{ 1955-1959 } \\
\hline Miller, GA & $\begin{array}{l}\text { The magical number } 7 \text {, plus or minus } 2 \text { : Some limits } \\
\text { on our capacity for processing information }\end{array}$ & Psych Rev & 1956 & 92.36 \\
\hline Stevens, SS & On the psychophysical law & Psych Rev & 1957 & 26.96 \\
\hline Peterson, LR; Peterson, MJ & Short-term retention of individual verbal items & $J$ Exp Psych & 1959 & 26.80 \\
\hline Easterbrook, JA & $\begin{array}{l}\text { The effect of emotion on cue utilization and the } \\
\text { organization of behavior }\end{array}$ & Psych Rev & 1959 & 22.96 \\
\hline Bruner, JS & On perceptual readiness & Psych Rev & 1957 & 16.83 \\
\hline Stevens, SS; Galanter, EH & $\begin{array}{l}\text { Ratio scales and category scales for a dozen } \\
\text { perceptual continua }\end{array}$ & $J E P$ & 1957 & 13.08 \\
\hline Gibson, JJ; Gibson, EJ & Perceptual learning: Differentiation or enrichment & Psych Rev & 1955 & 11.71 \\
\hline Brown, J & Some tests of the decay theory of immediate memory & QJEP & 1958 & 11.71 \\
\hline Deese, $\mathrm{J}$ & $\begin{array}{l}\text { On the prediction of occurrence of particular verbal } \\
\text { intrusions in immediate recall }\end{array}$ & $J E P$ & 1959 & 11.66 \\
\hline Simon, HA & Rational choice and the structure of the environment & Psych Rev & 1956 & 8.66 \\
\hline Guilford, JP & Three faces of intellect & Amer Psych & 1959 & 7.82 \\
\hline $\begin{array}{l}\text { Liberman, AM; Harris, KS; } \\
\text { Hoffman, HS; Griffith, BC }\end{array}$ & $\begin{array}{l}\text { The discrimination of speech sounds } \\
\text { within and across phoneme boundaries }\end{array}$ & $J E P$ & 1957 & 7.81 \\
\hline Stevens, SS & The direct estimation of sensory magnitudes: Loudness & Amer J Psych & 1956 & 7.57 \\
\hline Attneave, F; Arnoult, MD & The quantitative study of shape and pattern perception & Psych Bull & 1956 & 6.96 \\
\hline \multicolumn{5}{|l|}{$1960-1964$} \\
\hline Conrad, R & Acoustic confusions in immediate memory & Brit J Psych & 1964 & 18.76 \\
\hline Swets, JA; Tanner, WP; Birdsall, TG & Decision processes in perception & Psych Rev & 1961 & 13.27 \\
\hline Mednick, SA & The associative basis of the creative process & Psych Rev & 1962 & 13.15 \\
\hline Deutsch, JA; Deutsch, D & Attention: Some theoretical considerations & Psych Rev & 1963 & 12.17 \\
\hline
\end{tabular}


Tulving, E

Kendler, HH; Kendler, TS

Fitts, PM; Peterson, JR

Bruner, JS

Melton, AW

Gibson, JJ

Murdock, BB

Keppel, G; Underwood, BJ

Wason, PC

Klein, GS

Edwards, W

Campbell, DT

Neisser, U

Conrad, R; Hull, AJ

Treisman, AM

Miller, GA

Hirsh, IJ; Sherrick, CE

Yntema, DB; Trask, FP

Kleinsmith, LJ; Kaplan, S

Restle, F

\section{5-1969}

Sternberg, S

Liberman, AM; Cooper, FS;

Shankweiler, DP; Studdert-

Kennedy, M

Morton, J

Collins, AM; Quillian, MR

Waugh, NC; Norman, DA

Posner, MI; Keele, SW

Yin, RK

Tversky, A

Tulving, E; Pearlstone, Z

Shepard, RN

Paivio, A

Brown, R; McNeill, D

Crowder, RG; Morton, J

Sachs, JS

Treisman, AM

Posner, MI; Mitchell, RF

Keele, SW

Glanzer, M; Cunitz, AR

Underwood, BJ

Reicher, GM

Kahneman, D

Jensen, AR; Rohwer, WD

Underwood, BJ

Parducci, A
Subjective organization in free recall of unrelated words

Vertical and horizontal processes in problem-solving

Information capacity of discrete motor responses

The course of cognitive growth

Implications of short-term memory for a general theory of memory

Observations on active touch

Serial position effect of free recall

Proactive inhibition in short-term retention of single items

On the failure to eliminate hypotheses in a conceptual task

Semantic power measured through the interference of words with color naming

Behavioral decision theory

Blind variation and selective retention in creative thought as in other knowledge processes

Decision-time without reaction-time: Experiments in visual scanning

Information, acoustic confusion and memory span

Contextual cues in selective listening

Some psychological studies of grammar

Perceived order in different sense modalities

Recall as a search process

Paired-associate learning as a function of arousal and interpolated interval

The selection of strategies in cue learning

Discovery of processing stages: Extensions of

Donders' method

Perception of speech code

Interaction of information in word recognition

Retrieval time from semantic memory

Primary memory

On genesis of abstract ideas

Looking at upside-down faces

Intransitivity of preferences

Availability versus accessibility of information in memory for words

Recognition memory for words sentences and pictures

Mental imagery in associative learning and memory

Tip of tongue phenomenon

Precategorical acoustic storage (PAS)

Recognition memory for syntactic and semantic aspects of connected discourse

Strategies and models of selective attention

Chronometric analysis of classification

Movement control in skilled motor performance

Two storage mechanisms in free recall

Attributes of memory

Perceptual recognition as a function of meaningfulness of stimulus material

Method findings and theory in studies of visual masking

Stroop color-word test: A review

False recognition produced

by implicit verbal responses

Category judgment: A

range-frequency model
Acta Psych

1969

38.78

Psych Rev

1967

Psych Rev

1962

10.98

Psych Rev

10.74

$J E P$

9.71

Amer Psych 1964

$J M L$

9.24

8.19

8.15

7.74

7.59

7.33

7.17

6.92

6.78

6.64

6.59

6.13

5.92

5.72

5.26

5.04

Psych Rev 1969

28.05

$J M L$

1969

22.25

Psych Rev

1965

21.14

17.88

17.60

$J E P$

1969

17.55

Psych Rev

1969

17.53

$J M L$

14.55

Psych Rev

1967

14.38

$J M L$

14.09

Perc \& Psychophys $\quad 1969 \quad 14.05$

$\begin{array}{lll}\text { Perc \& Psychophys } & 1967 & 13.12\end{array}$

Psych Rev

1969

13.05

Psych Rev

1967

12.62

Psych Bull

1968

12.54

12.40

$J M L$

10.85

Psych Rev

1966

10.85
10.35

JEP

1969

Psych Bull

1968

10.15

Acta Psych

1966

9.28

$J E P$

1965

9.25

Psych Rev

1965

8.80 
Peterson, CR; Beach, LR

Norman, DA

Reber, AS

Clark, $\mathrm{HH}$

Oldfield, RC; Wingfield, A

Wason, PC

Levine, $\mathrm{M}$

Poulton, EC

Harris, CS

Smith, EE

Sternberg, S

Keele, SW; Posner, MI

Hyde, TS; Jenkins, JJ

Shankweiler, DP; Studdert-

Kennedy, M

Bower, GH; Clark, MC; Lesgold,

AM; Winzenz, D

Bamber, D

Ekstrand, BR; Wallace, WP;

Underwood, BJ

Rabbitt, PMA

Simon, Jr

\section{0-1974}

Craik, FIM; Lockhart, RS

Tversky, A; Kahneman, D

Tulving, E; Thomson, DM

Kahneman, D; Tversky, A

Eriksen, BA; Eriksen, CW

Laberge, D; Samuels, SJ

Chase, WG; Simon, HA

Meyer, DE; Schvaneveldt, RW

Tversky, A

Johansson, G

Kahneman, D; Tversky, A

Bransford, JD; Johnson, MK

Smith, EE; Shoben, EJ; Rips, LJ

Posner, MI; Boies, SJ

Tversky, A; Kahneman, D

Buschke, $\mathrm{H}$

Bransford, JD; Franks, JJ

Pylyshyn, ZW

Liberman, IY; Shankweiler, D;

Fischer, FW; Carter, B

Turvey, MT

Roenker, DL; Thompson, CP;

Brown, SC

Haviland, SE; Clark, HH
Man as an intuitive statistician

Psych Bull

1967

Toward a theory of memory and attention

Implicit learning of artificial grammars

Linguistic processes in deductive reasoning

Response latencies in naming objects

Reasoning about a rule

Hypothesis behavior by humans during

discrimination learning

New psychophysics: Six models for magnitude estimation

Perceptual adaptation to inverted, reversed, and displaced vision

Choice reaction time: An analysis of major theoretical positions

Two operations in character recognition: Some evidence from reaction-time measurements

Processing of visual feedback in rapid movements

Differential effects of incidental tasks on organization of recall of a list of highly associated words

Identification of consonants and vowels presented to left and right ears

Hierarchical retrieval schemes in recall of categorized word lists

Reaction times and error rates for same-different judgments of multidimensional stimuli

A frequency theory of verbal-discrimination learning

Errors and error correction in choice-response tasks

Reactions toward source of stimulation

Levels of processing: A framework for memory research

Availability: Heuristic for judging frequency and probability

Encoding specificity and retrieval processes in episodic memory

Psychology of prediction

Effects of noise letters upon identification of a target letter in a nonsearch task

Toward a theory of automatic information processing in reading

Perception in chess

Facilitation in recognizing pairs of words: Evidence of a dependence between retrieval operations

Elimination by aspects: Theory of choice

Visual-perception of biological motion and a model for its analysis

Subjective probability: Judgment of representativeness

Contextual prerequisites for understanding: Some investigations of comprehension and recall

Structure and process in semantic memory: Featural model for semantic decisions

Components of attention

Belief in law of small numbers

Selective reminding for analysis of memory and learning

Abstraction of linguistic ideas

What mind's eye tells minds brain: Critique of mental imagery

Explicit syllable and phoneme segmentation in young child

Peripheral and central processes in vision: Inferences from an information-processing analysis of masking with patterned stimuli

Comparison of measures for estimation of clustering in free recall

What's new: Acquiring new information as a process in comprehension $\begin{array}{lll}\text { Psych Rev } & 1968 & 8.54\end{array}$

$\begin{array}{lll}J M L & 1967 & 8.26\end{array}$

$\begin{array}{ll}\text { Psych Rev } & 1969\end{array}$

$\begin{array}{lll}\text { QJEP } & 1965 & 7.95\end{array}$

$\begin{array}{lll}Q J E P & 1968 & 7.68\end{array}$

$\begin{array}{lll}J E P & 1966 & 7.65\end{array}$

$\begin{array}{lll}\text { Psych Bull } & 1968\end{array}$

$\begin{array}{ll}\text { Psych Rev } & 1965\end{array}$

$\begin{array}{lll}\text { Psych Bull } & 1968\end{array}$

Perc \& Psychophys $\quad 1967$

JEP 1968

$\begin{array}{lll}J E P & 1969 & 6.30\end{array}$

$\begin{array}{lll}\text { QJEP } & 1967\end{array}$

$\begin{array}{lll}J M L & 1969 & 6.25\end{array}$

$\begin{array}{ll}\text { Perc \& Psychophys } & 1969\end{array}$

$\begin{array}{ll}\text { Psych Rev } & 1966 \quad 5.88\end{array}$

$\begin{array}{lll}J E P & 1966 & 5.84\end{array}$

$\begin{array}{lll}J E P & 1969 & 5.73\end{array}$

$J M L$

1972

87.08

$\begin{array}{lll}\text { Cog Psych } & 1973 & 51.11\end{array}$

$\begin{array}{lll}\text { Psych Rev } & 1973 & 42.89\end{array}$

$\begin{array}{lll}\text { Psych Rev } & 1973 & 41.08\end{array}$

$\begin{array}{lll}\text { Perc \& Psychophys } & 1974 & 31.69\end{array}$

$\begin{array}{ll}\text { Cog Psych } & 1974\end{array}$

$\begin{array}{lll}\text { Cog Psych } & 1973 & 27.11\end{array}$

$\begin{array}{lll}\text { JEP } & 1971 & 26.24\end{array}$

$\begin{array}{ll}\text { Psych Rev } \quad 1972 & 24.19\end{array}$

$\begin{array}{lll}\text { Perc \& Psychophys } & 1973 & 23.19\end{array}$

$\begin{array}{lll}\text { Cog Psych } & 1972 & 23.00\end{array}$

$\begin{array}{lll}J M L & 1972 & 20.59\end{array}$

$\begin{array}{ll}\text { Psych Rev } & 1974\end{array}$

$\begin{array}{lll}\text { Psych Rev } & 1971 & 17.68\end{array}$

$\begin{array}{lll}\text { Psych Bull } & 1971 & 17.24\end{array}$

$\begin{array}{lll}J M L & 1973 & 16.86\end{array}$

$\begin{array}{lll}\text { Cog Psych } & 1971 & 16.53\end{array}$

$\begin{array}{lll}\text { Psych Bull } & 1973 & 16.17\end{array}$

$\begin{array}{lll}J & \text { Exp Child Psych } & 1974\end{array}$

$\begin{array}{lll}\text { Psych Rev } & 1973 & 14.72\end{array}$

$\begin{array}{lll}\text { Psych Bull } & 1971 & 13.92\end{array}$

$\begin{array}{lll}J M L & 1974 & 13.43\end{array}$ 
Appelle, S

Anderson, JR; Bower, GH

Bransford, JD; Barclay, JR;

Franks, JJ

Rips, LJ; Shoben, EJ; Smith, EE

Rosch, EH

Lichtenstein, S; Slovic, P

Pascual-Leone, J

Reed, SK

Loftus, EF; Palmer, JC

Wickens, DD

Clark, HH; Chase, WG

Marks, DF

Wing, AM; Kristofferson, AB

Forster, KI; Chambers, SM

Rundus, D

Phillips, WA

Wheeler, DD

Eriksen, CW; Hoffman, JE

Eriksen, CW; Hoffman, JE

Erdelyi, MH

Anderson, NH

Posner, MI; Keele, SW

Milner, PM

Meyer, DE; Schvaneveldt, RW; Ruddy, MG

Stevens, SS

Bregman, AS; Campbell, J

Garner, WR; Felfoldy, GL

Rubenstein, H; Lewis, SS

Rubenstein, MA

Craik, FIM; Watkins, MJ

Bjork, RA; Whitten, WB

\section{5-1979}

Nisbett, RE; Wilson, TD

Shiffrin, RM; Schneider, W

Tversky, A

Schneider, W; Shiffrin, RM

Collins, AM; Loftus, EF

Hasher, L; Zacks, RT

Kintsch, W; Vandijk, TA

Rosch, E; Mervis, CB; Gray,

WD; Johnson, DM;

Boyesbraem, $\mathrm{P}$

Craik, FIM; Tulving, E

Rosch, E; Mervis, CB
Perception and discrimination as a function of stimulus orientation: Oblique effect in man and animals

Recognition and retrieval processes in free-recall

Sentence memory: Constructive versus interpretive approach

Semantic distance and verification of semantic relations

Natural categories

Reversals of preference between bids and choices in gambling decisions

A mathematical model for transition rule in Piaget's developmental stages

Pattern recognition and categorization

Reconstruction of automobile destruction: Example of interaction between language and memory

Encoding categories of words: Empirical approach to meaning

Process of comparing sentences against pictures

Visual imagery differences in recall of pictures

Response delays and timing of discrete motor responses

Lexical access and naming time

Analysis of rehearsal processes in free recall

Distinction between sensory storage and short-term visual memory

Processes in word recognition

Extent of processing of noise elements during selective encoding from visual displays

Temporal and spatial characteristics of selective encoding from visual displays

New look at new look: Perceptual defense and vigilance

Functional measurement and psychophysical judgment

Retention of abstract ideas

Model for visual shape recognition

Functions of graphemic and phonemic codes in visual word recognition

Issues in psychophysical measurement

Primary auditory stream segregation and perception of order in rapid sequences of tones

Integrality of stimulus dimensions in various types of information processing

Evidence for phonemic recording in visual word recognition

Role of rehearsal in short-term memory

Recency-sensitive retrieval processes in long-term free recall

Telling more than we can know: Verbal reports on mental processes

Controlled and automatic human information processing: II. Perceptual learning, automatic attending, and a general theory

Features of similarity

Controlled and automatic human information Processing: I. Detection, search, and attention Spreading activation theory of semantic processing

Automatic and effortful processes in memory

Toward a model of text comprehension and production

Basic objects in natural categories

Depth of processing and retention of words in episodic memory

Family resemblances: Studies in internal structure of categories
Psych Bull

1972

12.89

Psych Rev

1972

11.95

Cog Psych

1972

11.86

$J M L$

11.81

Cog Psych

1973

11.61

$J E P$

1973

11.58

Acta Psych

11.13

Cog Psych

1970

10.92

$J M L$

10.89

Psych Rev

10.82

Cog Psych

10.70

Brit J Psych

10.58

Perc \& Psychophys

10.50

$J M L$

9.97

JEP

1973

9.53

Perc \& Psychophys

Cog Psych

1970

9.13

Perc \& Psychophys

Perc \& Psychophys

1972

8.84

Psych Rev

1974

8.26

Psych Rev

1970

1970

8.10

$J E P$

1974

Psych Rev

$\mathrm{Mem} \& \mathrm{Cog}$

Psych Rev

1971

1971

JEP

1970

7.54

$J M L$

1971

7.50

$J M L$

1973

7.28

Cog Psych

1974

7.23

Psych Rev

1977

94.28

Psych Rev

1977

Psych Rev

1977

64.22

Psych Rev

1977

64.09

Psych Rev 1975

63.74

JEP:Gen

1979

53.13

Psych Rev

1978

50.13

Cog Psych

1976

49.73

JEP:Gen

1975

44.82

Cog Psych

1975 
Neely, JH

Medin, DL; Schaffer, MM

Rosch, E

Navon, D

Mandler, JM

Norman, DA; Bobrow, DG

Schmidt, RA

Bower, GH; Black, JB; Turner, TJ

McClelland, JL

Ratcliff, R

Morris, CD; Bransford, JD;

Franks, JJ

Breitmeyer, BG; Ganz, L

Baddeley, AD; Thomson, N;

Buchanan, M

Navon, D; Gopher, D

Flavell, JH

Thorndyke, PW

Fischhoff, B

Slamecka, NJ; Graf, P

Schmidt, RA; Zelaznik, H; Hawkins, B; Frank, JS; Quinn, JT

Pribram, KH; Mcguinness, D

Scarborough, DL; Cortese, C;

Scarborough, HS

Marslenwilson, WD; Welsh, A

Slovic, P; Fischhoff, B;

Lichtenstein, $\mathrm{S}$

Sternberg, S

Glushko, RJ

Swinney, DA

Loftus, EF; Miller, DG; Burns, $\mathrm{H}$

Lee, DN

Eriksen, CW; Schultz, DW

Vandenberg, SG; Kuse, AR

Anderson, JR

Einhorn, HJ; Hogarth, RM

Lichtenstein, S; Slovic, P; Fischhoff, BL; Layman, M; Combs, B

Brown, R; Kulik, J

Morais, J; Cary, L; Alegria, J;

Bertelson, $\mathrm{P}$

Anderson, RC; Pichert, JW

Rosch, E

Neill, WT
Semantic priming and retrieval from lexical memory: Roles of inhibition-less spreading activation and limited-capacity attention

Context theory of classification learning

Cognitive representations of semantic categories

Forest before trees: Precedence of global features in visual-perception

Remembrance of things past: Story structure and recall

Data-limited and resource-limited processes

Schema theory of discrete motor skill learning

Scripts in memory for text

Time relations of mental processes: Examination of systems of processes in cascade

Theory of memory retrieval

Levels of processing versus transfer appropriate processing

Implications of sustained and transient channels for theories of visual-pattern masking, saccadic sup-

pression, and information-processing

Word length and structure of short-term-memory

Economy of the human-processing system

Meta-cognition and cognitive monitoring: New area of cognitive-developmental inquiry

Cognitive structures in comprehension and memory of narrative discourse

Hindsight not equal to foresight: Effect of outcome

knowledge on judgment under uncertainty

Generation effect: Delineation of a phenomenon

Motor-output variability: Theory for the accuracy of rapid motor acts

Arousal, activation, and effort in control of attention

Frequency and repetition effects in lexical memory

Processing interactions and lexical access during word recognition in continuous speech

Behavioral decision-theory

Memory scanning: New findings and current controversies

Organization and activation of orthographic

knowledge in reading aloud

Lexical access during sentence comprehension: (Re) consideration of context effects

Semantic integration of verbal information into a visual memory

Theory of visual control of braking based on information about time-to-collision

Information-processing in visual-search:

Continuous-flow conception and

experimental results

Mental rotations, a group test of 3-dimensional spatial visualization

Arguments concerning representations for mental imagery

Confidence in judgment: Persistence of illusion of validity

Judged frequency of lethal events

Flashbulb memories

Does awareness of speech as a sequence of phones arise spontaneously

Recall of previously unrecallable information following a shift in perspective

Cognitive reference points

Inhibitory and facilitatory processes in selective attention
JEP:Gen

1977

40.03

Psych Rev

1978

34.52

JEP:Gen

1975

Cog Psych

34.06

Cog Psych

1977

Cog Psych

1975

1975

1979

1979

1978

1977

1976

$J M L$

1975

20.94

Psych Rev

1979

20.77

Amer Psych

1979

20.57

Cog Psych

1977

20.25

$J E P: H P P$

1975

19.88

JEP:LMC

1978

19.58

Psych Rev

1979

19.57

Psych Rev

1975

18.88

JEP:HPP

1977

18.38

Cog Psych

1978

17.74

Ann Rev Psych

1977

17.66

QJEP

17.53

$J E P: H P P$

$J M L$

17.33

$J E P: L M C$

17.06

Perc

16.39

Perc \& Psychophys

15.50

Perc Mot Skills

15.03

Psych Rev

14.52

Psych Rev

14.52

$J E P: L M C$

14.26

$\operatorname{Cog}$

14.22

Cog

1977

14.17

$J M L$

12.32

Cog Psych

1978

11.15

JEP:HPP

11.00 
Anderson, JA; Silverstein, JW; Ritz, SA; Jones, RS

Rayner, K

Posner, MI; Nissen, MJ; Klein, RM

Kelso, JAS; Southard, DL; Goodman, D

Kosslyn, SM; Ball, TM; Reiser, BJ

\section{0-1984}

Treisman, AM; Gelade, G

Posner, MI

Bower, GH

Zajonc, RB

McClelland, JL; Rumelhart, DE

Daneman, M; Carpenter, PA

Jacoby, LL; Dallas, M

Kahneman, D; Tversky, A

Mandler, G

Chi, MTH; Feltovich, PJ; Glaser,

Posner, MI; Snyder, CR;

Davidson, BJ

Wimmer, H; Perner, J

Ericsson, KA; Simon, HA

Anderson, JR

Gillund, G; Shiffrin, RM

Duncan, J

Johnson, MK; Raye, CL

Just, MA; Carpenter, PA

Marcel, AJ

Gick, ML; Holyoak, KJ

Balota, DA; Chumbley, JI

Tversky, A; Kahneman, D

Graf, P; Mandler, G

Yantis, S; Jonides, J

Tulving, E; Schacter, DL; Stark, HA

Einhorn, HJ; Hogarth, RM

Payne, JW

Jacoby, LL

Logan, GD; Cowan, WB

Gick, ML; Holyoak, KJ

Jacoby, LL

Treisman, A; Schmidt, H

Mervis, CB; Rosch, E

Hoffman, DD; Richards, WA

Raaijmakers, JGW; Shiffrin, RM

Fischer, KW
Distinctive features, categorical perception, and probability learning: Some applications of a neural model

Eye-movements in reading and information processing

Visual dominance: Information-processing account of its origins and significance

Coordination of two-handed movements

Visual images preserve metric spatial information: Evidence from studies of image scanning

Feature-integration theory of attention

Orienting of attention

Mood and memory

Feeling and thinking: Preferences need no inferences

An interactive activation model of context effects in

letter perception: I. An account of basic findings

Individual differences in working memory and reading

On the relationship between autobiographical memory and perceptual learning

Choices, values, and frames

Recognizing: The judgment of previous occurrence

Categorization and representation of physics

problems by experts and novices

Attention and the detection of signals

Beliefs about beliefs: Representation and constraining function of wrong beliefs in young children's understanding of deception

Verbal reports as data

Acquisition of cognitive skill

A retrieval model for both recognition and recall

Selective attention and the organization of visua information

Reality monitoring

Theory of reading: From eye fixations to comprehension

Conscious and unconscious perception: Experiments on visual masking and word recognition

Schema induction and analogical transfer

Are lexical decisions a good measure of lexical access: The role of word-frequency in the neglected decision stage

Extensional versus intuitive reasoning: The conjunction fallacy in probability judgment

Activation makes words more accessible, but not necessarily more retrievable

Abrupt visual onsets and selective attention: Evidence from visual-search

Priming effects in word-fragment completion are independent of recognition memory

Behavioral decision-theory: Processes of judgment and choice

Contingent decision behavior

Remembering the data: Analyzing interactive processes in reading

On the ability to inhibit thought and action: A theory of an act of control

Analogical problem-solving

Perceptual enhancement: Persistent effects of an experience

Illusory conjunctions in the perception of objects

Categorization of natural objects

Parts of recognition

Search of associative memory

A theory of cognitive-development: The control and construction of hierarchies of skills
Psych Rev

1977

10.72

Psych Bull

1978

10.32

Psych Rev

1976

10.06

$J E P: H P P$

9.93

$J E P: H P P$

1978

9.90

$\operatorname{Cog}$ Psych

106.66

QJEP

1980

80.48

Amer Psych

1980

76.68

Amer Psych

1981

71.97

Psych Rev

1980

63.71

$J M L$

1980

52.31

JEP:Gen

50.50

Amer Psych

46.84

Psych Rev

1984

1980

44.93

Cog Sci

1981

42.43

JEP:Gen

1980

40.79

$\operatorname{Cog}$

1983

40.58

Psych Rev

1980

39.93

Psych Rev

1982

31.07

Psych Rev

1984

30.88

JEP:Gen

1984

29.60

Psych Rev

1981

25.39

Psych Rev

1980

24.69

Cog Psych

1983

24.50

Cog Psych

1983

24.38

JEP:HPP

1984

23.52

Psych Rev

1983

23.31

$J M L$

1984

JEP:HPP

1984

JEP:LMC

1982

20.96

Ann Rev Psych

1981

20.75

Psych Bull

1982

20.48

$J M L$

1983

19.12

Psych Rev

1984

19.00

Cog Psych

1980

18.97

JEP:LMC

1983

18.31

Cog Psych

1982

18.30

Ann Rev Psych

1981

18.18

$\operatorname{Cog}$

1984

17.72

Psych Rev

1981

17.71

Psych Rev

1980 
Marslenwilson, W; Tyler, LK

Rumelhart, DE; McClelland, JL

Norman, DA

Forster, KI; Davis, C

Frazier, L; Rayner, K

Seidenberg, MS; Waters, GS;

Barnes, MA; Tanenhaus, MK

Glaser, R

Alba, JW; Hasher, L

Murdock, BB

Case, R; Kurland, DM;

Goldberg, J

Rosenbaum, DA

Koriat, A; Lichtenstein, S;

Fischhoff, B

Seidenberg, MS; Waters, GS;

Sanders, M; Langer, P

Barsalou, LW

Marcel, AJ

Stanovich, KE; Cunningham,

AE; Cramer, BB

Jacoby, LL; Witherspoon, D

Salmoni, AW; Schmidt, RA;

Walter, CB.

Duncan, J

\section{5-1989}

Biederman, I

Seidenberg, MS; Mcclelland, JL

Schacter, DL

Duncan, J; Humphreys, GW

Logan, GD

Wagner, RK; Torgesen, JK

Stanovich, KE

Bruce, V; Young, A

Treisman, A; Gormican, S

Dell, GS

Kintsch, W

Nissen, MJ; Bullemer, P

Wolfe, JM; Cave, KR; Franzel, SL

Nosofsky, RM

Kahneman, D; Miller, DT

Murphy, GL; Medin, DL

Blaney, $\mathrm{PH}$

Richardson-Klavehn, A; Bjork, RA

Tipper, SP

Hintzman, DL
Temporal structure of spoken

language understanding

An interactive activation model of context effects in letter perception: II. The contextual enhancement effect and some tests and extensions of the model

Categorization of action slips

Repetition priming and frequency attenuation in exical access

Making and correcting errors during sentence comprehension: Eye movements in the analysis of structurally ambiguous sentences

When does irregular spelling or pronunciation influence word recognition

Education and thinking: The role of knowledge

Is memory schematic?

A theory for the storage and retrieval of item and associative information

Operational efficiency and the growth of short-termmemory span

Human movement initiation: Specification of arm, direction, and extent

Reasons for confidence

Prelexical and postlexical loci of contextual effects on word recognition

Ad hoc categories

Conscious and unconscious perception: An approach to the relations between phenomenal experience and perceptual processes

Assessing phonological awareness in kindergartenchildren: Issues of task comparability

Remembering without awareness

Knowledge of results and motor learning: A review and critical reappraisal

The locus of interference in the perception of simultaneous stimuli

Recognition-by-components: A theory of human image understanding

A distributed, developmental model of word recognition and naming

Implicit memory: History and current status

Visual search and stimulus similarity

Toward an instance theory of automatization

The nature of phonological processing and its causal role in the acquisition of reading skills

Matthew effects in reading: Some consequences of individual-differences in the acquisition of literacy

Understanding face recognition

Feature analysis in early vision: Evidence from search asymmetries

A spreading-activation theory of retrieval in sentence production

The role of knowledge in discourse comprehension: A construction integration model

Attentional requirements of learning: Evidence from performance-measures

Guided search: An alternative to the feature integration model for visual-search

Attention, similarity, and the identification-

categorization relationship

Norm theory: Comparing reality to its alternatives

The role of theories in conceptual coherence

Affect and memory: A review

Measures of memory

The negative priming effect: Inhibitory priming by ignored objects

Schema abstraction in a multiple-trace memory model
$\operatorname{Cog}$

1980

16.97

Psych Rev

1982

16.93

Psych Rev

1981

16.82

$J E P: L M C$

1984

16.56

Cog Psych

1982

16.19

$J M L$

1984

16.08

Amer Psych

1984

16.04

Psych Bull

15.88

Psych Rev

1982

15.81

$J$ Exp Child Psych

1982

15.81

JEP:Gen

1980

15.79

$J E P: L M C$

1980

15.72

Mem \& $\mathrm{Cog}$

1984

15.72

$\mathrm{Mem} \& \mathrm{Cog}$

1983

15.62

Cog Psych

1983

15.35

J Exp Child Psych

1984

15.00

Can J Exp Psych

1982

14.93

Psych Bull

1984

14.04

Psych Rev

1980

13.83

Psych Rev

Psych Rev

JEP:LMC

Psych Rev

Psych Rev

1988

48.43

Psych Bull

1987

45.73

Read Res Quart

1986

45.30

Brit J Psych

1986

43.91

Psych Rev

1988

43.67

Psych Rev

1986

41.22

Psych Rev

1988

41.05

Cog Psych

1987

37.00

JEP:HPP

1989

35.70

JEP:Gen

1986

34.78

Psych Rev

1986

34.57

Psych Rev

1985

34.33

Psych Bull

1986

32.61

Ann Rev Psych

32.33

QJEP

1985

31.83

Psych Rev

1986

31.70 
Fodor, JA; Pylyshyn, ZW

Liberman, AM; Mattingly, IG

Reber, AS

McClelland, JL; Elman, JL

Eriksen, CW; Stjames, JD

Tversky, A; Sattath, S; Slovic, P

Diamond, R; Carey, S

Chi, MTH; Bassok, M; Lewis,

MW; Reimann, P; Glaser, R

Muller, HJ; Rabbitt, PMA

Tulving, E

Blaxton, TA

Hintzman, DL

Smolensky, P

Holender, D

Gardiner, JM

Hastie, R; Park, B

Eriksen, CW; Yeh, YY

Marslenwilson, WD

Cheng, PW; Holyoak, KJ

Turner, ML; Engle, RW

Meyer, DE; Kornblum, S;

Abrams, RA; Wright, CE;

Smith, JEK

Medin, DL

Cowan, $\mathrm{N}$

Sweller, J

Laberge, D; Brown, V

Cerella, J

Grossberg, S; Mingolla, E

Tarr, MJ; Pinker, S

Van Orden, GC

Anderson, JR

Treisman, A; Souther, J

Payne, JW; Bettman, JR;

Johnson, EJ

McClelland, JL; Rumelhart, DE.

Jonides, J; Yantis, S

Jacoby, LL.; Woloshyn, V;

Kelley, C

\section{0-1994}

Johnson, MK; Hashtroudi, S;

Lindsay, DS

Jacoby, LL

Macleod, CM
Connectionism and cognitive architecture: A critical analysis

The motor theory of speech perception revised

Implicit learning and tacit knowledge

The trace model of speech perception

Visual-attention within and around the field of focal attention: A zoom lens model

Contingent weighting in judgment and choice

Why faces are and are not special: An effect of expertise

Self-explanations: How students study and use examples in learning to solve problems

Reflexive and voluntary orienting of visual attention: Time course of activation and resistance to interruption How many memory systems are there?

Investigating dissociations among memory measures: Support for a transfer-appropriate processing framework

Judgments of frequency and recognition memory in a multiple-trace memory model

On the proper treatment of connectionism

Semantic activation without conscious identification in dichotic listening, parafoveal vision, and visual masking: A survey and appraisal

Functional aspects of recollective experience

The relationship between memory and judgment depends on whether the judgment task is memorybased or online

Allocation of attention in the visual field

Functional parallelism in spoken word recognition

Pragmatic reasoning schemas

Is working memory capacity task dependent

Optimality in human motor-performance: Ideal control of rapid aimed movements

Concepts and conceptual structure

Evolving conceptions of memory storage, selective attention, and their mutual constraints within the human information-processing system

Cognitive load during problem-solving: Effects on learning

Theory of attentional operations in shape identification

Information-processing rates in the elderly

Neural dynamics of form perception: Boundary completion, illusory figures, and neon color spreading

Mental rotation and orientation-dependence in shape recognition

A rows is a rose: Spelling, sound and reading

Skill acquisition: Compilation of weak-method problem solutions

Search asymmetry: A diagnostic for preattentive processing of separable features.

Adaptive strategy selection in decision making

Distributed memory and the representation of general and specific information

Uniqueness of abrupt visual onset in capturing attention

Becoming famous without being recognized: Unconscious influences of memory produced by dividing attention.

Source monitoring

A process dissociation framework: Separating automatic from intentional uses of memory

Half a century of research on the Stroop effect: An integrative review
Psych Bull

1993

79.75

Co

Cog

29.48

JEP:Gen

29.04

Cog Psych

27.80

27.70

26.96

26.86

26.83

JEP:Gen

26.30

JEP:HPP

26.15

Amer Psych

24.75

$J E P: L M C$

1985

24.55

Psych Rev

1988

23.86

$B B S$

1988

23.43

$B B S$

1986

22.00

Mem \& $\mathrm{Cog}$

1988

22.00

Psych Rev

1986

21.43

JEP:HPP

1985

20.63

$\mathrm{Cog}$

1987

20.41

20.04

$J M L$

1989

20.00

Psych Rev

1988

19.33

Amer Psych

1989

18.80

Psych Bull

1988

18.62

$\operatorname{Cog} S c i$

1988

18.57

Psych Rev

1989

18.15

1985

18.04

Psych Rev

1985

18.04

Cog Psych

1989

17.90

Mem \& $\mathrm{Cog}$

1987

17.86

Psych Rev

17.86

JEP:Gen

17.83

$J E P: L M C$

JEP:Gen

Perc \& Psychophys

1988

17.52

JEP:Gen

1989

16.95

$J M L$

1991

77.11

Psych Bull

1991
Psych Bull 
Just, MA; Carpenter, PA

Wolfe, JM

Coltheart, M; Curtis, B; Atkins, P; Haller, M

Wegner, DM

Ericsson, KA; Krampe, RT;

Teschromer, $\mathrm{C}$

MacDonald, MC; Pearlmutter,

NJ; Seidenberg, MS

Ceci, SJ; Bruck, M

Roediger, HL

Raymond, JE; Shapiro, KL;

Arnell, KM

Pashler, $\mathrm{H}$

Cohen, JD; Dunbar, K; Mcclelland, JL

Folk, CL; Remington, RW;

Johnston, JC

Kruschke, JK

Kornblum, S; Hasbroucq, T; Osman, A

Tanaka, JW; Farah, MJ

Shanks, DR; Stjohn, MF

Kahneman, D; Treisman, A; Gibbs, BJ

Jacoby, LL; Toth, JP; Yonelinas, AP

Treisman, A; Sato, S

Graesser, AC; Singer, M; Trabasso, $\mathrm{T}$

Yantis, S; Jonides, J

Chi, MTH; Deleeuw, N; Chiu,

$\mathrm{MH}$; Lavancher, C

Kyllonen, PC; Christal, RE

Payne, JW; Bettman, JR;

Johnson, EJ

Hummel, JE; Biederman, I

Light, LL

Gigerenzer, G; Hoffrage, U;

Kleinbolting, $\mathrm{H}$

Egly, R; Driver, J; Rafal, RD

Ericsson, KA; Charness, N

Wilson, TD; Brekke, N

McKoon, G; Ratcliff, R

Bundesen, $\mathrm{C}$

Jescheniak, JD; Levelt, WJM

Biederman, I; Gerhardstein, PC

Norris, D

Van Orden, GC; Stone, GO;

Pennington, $\mathrm{BF}$

Trueswell, JC; Tanenhaus, MK;

Garnsey, SM

Christianson, SA

Dejong, R; Liang, CC; Lauber, E
A capacity theory of comprehension: Individual differences in working memory

Guided search 2.0: A revised model of visual-search

Models of reading aloud: Dual-route and paralleldistributed-processing approaches

Ironic processes of mental control

The role of deliberate practice in the acquisition of expert performance

Lexical nature of syntactic ambiguity resolution

Suggestibility of the child witness: A historical review and synthesis

Implicit memory: Retention without remembering

Temporary suppression of visual processing in an RSVP task: An attentional blink

Dual-task interference in simple tasks: Data and theory

On the control of automatic processes: A parallel distributed-processing account of the Stroop effect Involuntary covert orienting is contingent on attentional control settings

ALCOVE: An exemplar-based connectionist model of category learning

Dimensional overlap: Cognitive basis for stimulusresponse compatibility — A model and taxonomy

Parts and wholes in face recognition

Characteristics of dissociable human learning systems

The reviewing of object files: Object-specific integration of information

Separating conscious and unconscious influences of memory: Measuring recollection

Conjunction search revisited

Constructing inferences during narrative text comprehension

Abrupt visual onsets and selective attention: Voluntary versus automatic allocation

Eliciting self-explanations improves understanding

Reasoning ability is (little more than) workingmemory capacity

Behavioral decision research: A constructive processing perspective

Dynamic binding in a neural network for shape recognition

Memory and aging: Four hypotheses in search of data

Probabilistic mental models: A Brunswikian theory of confidence

Shifting visual attention between objects and locations: Evidence from normal and parietal lesion subjects.

Expert performance: Its structure and acquisition

Mental contamination and mental correction:

Unwanted influences on judgments and evaluations Inference during reading

A theory of visual attention

Word-frequency effects in speech production: Retrieval of syntactic information and of phonological form

Recognizing depth-rotated objects: Evidence and conditions for 3-dimensional viewpoint invariance

Shortlist: A connectionist model of continuous speech recognition

Word identification in reading and the promise of subsymbolic psycholinguistics

Semantic influences on parsing: Use of thematic role information in syntactic ambiguity resolution

Emotional-stress and eyewitness memory: A criticalreview

Conditional and unconditional automaticity: A dualprocess model of effects of spatial stimulus-response correspondence
Psych Rev

1992

64.41

$P B \& R$

1994

Psych Rev

1993

41.44

Psych Rev

1994

41.07

Psych Rev

1993

40.25

Psych Rev

1994

36.07

Psych Bull

1993

34.31

Amer Psych

1990

33.84

JEP:HPP

33.06

Psych Bull

32.47

Psych Rev

1994

32.26

JEP:HPP

1992

31.65

Psych Rev

1992

31.24

Psych Rev

1990

31.11

QJEP

1993

31.06

$B B S$

1994

30.53

Cog Psych

1992

29.12

JEP:Gen

1993

27.06

$J E P: H P P$

1990

26.79

Psych Rev

1994

26.40

JEP:HPP

1990

26.16

$\operatorname{Cog} S c i$

1994

24.80

Int

1990

24.68

Ann Rev Psych

1992

23.47

Psych Rev

1992

22.53

Ann Rev Psych

1991

22.00

Psych Rev

1991

21.94

JEP:Gen

1994

21.67

Amer Psych

1994

21.47

Psych Bull

1994

21.07

Psych Rev

1992

20.53

Psych Rev

1990

20.32

JEP:LMC

1994

19.67

JEP:HPP

1993

19.38

$\operatorname{Cog}$

1994

19.20

Psych Rev

1990

18.79

$J M L$

1994

18.60

Psych Bull

1992

18.53

$J E P \cdot H P P$

1994

18.47 
Carpenter, PA; Just, MA; Shell, P

Dehaene, S; Bossini, S; Giraux, P

Lindenberger, U; Baltes, PB

Kramer, AF; Humphrey, DG; Larish, JF; Logan, GD; Strayer, DL

Hasher, L; Stolzfus, ER; Zacks,

RT; Rypma, B

Eysenck, MW; Calvo, MG

Hulme, C; Maughan, S; Brown, GDA

Cave, KR; Wolfe, JM

Yonelinas, AP

O’Regan, JK

Schmidt, RA; Bjork, RA

Kroll, JF; Stewart, E

Fischer, B; Weber, $\mathrm{H}$

Cohen, A; Ivry, RI; Keele, SW

Bacon, WF; Egeth, HE

Theeuwes, J

King, J; Just, MA

Griffin, D; Tversky, A

Gerstadt, CL; Hong, YJ;

Diamond, A

\section{5-1999}

Levelt, WJM; Roelofs, A; Meyer, AS

Salthouse, TA

Roediger, HL; Mcdermott, KB

Rayner, K

Barsalou, LW

Plaut, DC; McClelland, JL;

Seidenberg, MS; Patterson, K

Bargh, JA; Chartrand, TL

Rogers, RD; Monsell, S

Rensink, RA; O’Regan, JK; Clark, JJ

Engle, RW; Tuholski, SW; Laughlin, JE; Conway, ARA

Ericsson, KA; Kintsch, W

Landauer, TK; Foltz, PW;

Laham, D

Baddeley, A; Gathercole, S;

Papagno, C

Sloman, SA

Farah, MJ; Wilson, KD; Drain,

M; Tanaka, JN

Zwaan, RA; Radvansky, GA

Chun, MM; Potter, MC
What one intelligence-test measures: A theoretical account of the processing in the raven progressive matrices test

The mental representation of parity and number magnitude

Sensory functioning and intelligence in old-age: A strong connection

Aging and inhibition: Beyond a unitary view of inhibitory processing in attention

Age and inhibition

Anxiety and performance: The processing efficiency theory

Memory for familiar and unfamiliar words: Evidence for a long-term memory contribution to short-term memory span

Modeling the role of parallel processing in visual search

Receiver-operating characteristics in recognition memory: Evidence for a dual-process model

Solving the real mysteries of visual-perception: The world as an outside memory

New conceptualizations of practice: Common principles in three paradigms suggest new concepts for training

Category interference in translation and picture naming: Evidence for asymmetric connections between bilingual memory representations

Express saccades and visual attention

Attention and structure in sequence learning

Overriding stimulus-driven attentional capture

Perceptual selectivity for color and form

Individual differences in syntactic processing: The role of working memory

The weighing of evidence and the determinants of confidence

The relationship between cognition and action: Performance of children $31 / 2-7$ years old on a Stroop-like day-night test

A theory of lexical access in speech production

The processing-speed theory of adult age differences in cognition

Creating false memories: Remembering words not presented in lists

Eye movements in reading and information processing: 20 years of research

Perceptual symbol systems

Understanding normal and impaired word reading:

Computational principles in quasi-regular domains

The unbearable automaticity of being

Costs of a predictable switch between simple cognitive tasks

To see or not to see: The need for attention to perceive changes in scenes

Working memory, short-term memory, and genera fluid intelligence: A latent-variable approach

Long-term working memory

An introduction to latent semantic analysis

The phonological loop as a language learning device

The empirical case for two systems of reasoning

What is "special" about face perception?

Situation models in language comprehension and memory

A two-stage model for multiple-target detection in rapid serial visual presentation
Psych Rev

1990

18.32

JEP:Gen

1993

18.06

Psych \& Aging

1994

18.00

Psych \& Aging

1994

17.80

$J E P: L M C$

17.78

Cog \& Emot

17.76

$J M L$

1991

17.56

Cog Psych

1990

17.37

JEP:LMC

1994

17.33

Can J Exp Psych

1992

17.29

Psych Sci

1992

17.24

$J M L$

1994

17.20

$B B S$

1993

17.06

JEP:LMC

1990

16.84

Perc \& Psychophys

1994

16.20

Perc \& Psychophys

1992

$J M L$

16.00

Cog Psych

1992

15.94

15.88

$\operatorname{Cog}$

1994

15.40

$B B S$

79.80

Psych Rev

76.08

$J E P: L M C$

60.64

Psych Bull

60.45

$B B S$

56.60

Psych Rev

56.54

Amer Psych

53.60

JEP:Gen

1999

1995

53.14

Psych Sci

1997

44.33

JEP:Gen

1999

42.60

Psych Rev

1995

38.93

Disc Process

1998

38.82

Psych Rev

1998

35.55

Psych Bull

1996

33.38

Psych Rev

1998

27.64

Psych Bull

1998

27.45

$J E P: H P P$

1995 
Meiran, N

Simons, DJ; Levin, DT

Gigerenzer, G; Goldstein, DG

Share, DL

Gibson, E

Meyer, DE; Kieras, DE

Lavie, $\mathrm{N}$

Gigerenzer, G; Hoffrage, U

Hoffman, JE; Subramaniam, B

Findlay, JM; Walker, R

Ericsson, KA; Lehmann, AC

Reichle, ED; Pollatsek, A; Fisher,

DL; Rayner, K

Glenberg, AM

Egeth, HE; Yantis, S

Burgess, N; Hitch, GJ

Gentner, D; Markman, AB

Daneman, M; Merikle, PM

Caplan, D; Waters, GS

Frost, R

Donaldson, W

Driver, J; Davis, G; Ricciardelli, P; Kidd, P; Maxwell, E; BaronCohen, $\mathrm{S}$

Leopold, DA; Logothetis, NK

Craik, FIM; Govoni, R; Naveh-

Benjamin, M; Anderson, ND

Schacter, DL; Israel, L; Racine, C

Mody, M; Studdertkennedy, M; Brady, S

Shiffrin, RM; Steyvers, M

Hummel, JE; Holyoak, KJ

May, CP; Kane, MJ; Hasher, L

Fox, E

Payne, DG; Elie, CJ; Blackwell,

JM; Neuschatz, JS

Norman, KA; Schacter, DL

Goldstone, RL

$\mathrm{Lu}, \mathrm{CH}$; Proctor, RW

Kahneman, D; Tversky, A

Spieler, DH; Balota, DA; Faust, $\mathrm{ME}$

Henderson, JM; Hollingworth, A

Simons, DJ; Levin, DT
Reconfiguration of processing mode prior to task performance

Change blindness

Reasoning the fast and frugal way: Models of bounded rationality

Phonological recoding and self-teaching: Sine qua non of reading acquisition

Linguistic complexity: Locality of syntactic dependencies

A computational theory of executive cognitive processes and multiple-task performance: I. Basic mechanisms

Perceptual load as a necessary condition for selective attention

How to improve Bayesian reasoning without instruction: Frequency formats

The role of visual-attention in saccadic eye movements

A model of saccade generation based on parallel processing and competitive inhibition

Expert and exceptional performance: evidence of maximal adaptation to task constraints

Toward a model of eye movement control in reading

What memory is for

Visual attention: Control, representation, and time course

Memory for serial order: A network model of the phonological loop and its timing

Structure mapping in analogy and similarity

Working memory and language comprehension: A meta-analysis

Verbal working memory and sentence comprehension

Toward a strong phonological theory of visual word recognition: True issues and false trails

The role of decision processes in remembering and knowing

Gaze perception triggers reflexive visuospatial orienting

Multistable phenomena: Changing views in perception

The effects of divided attention on encoding and retrieval processes in human memory

Suppressing false recognition in younger and older adults: The distinctiveness heuristic

Speech perception deficits in poor readers: auditory processing or phonological coding?

Model for recognition memory: REM-retrieving effectively from memory

Distributed representations of structure: A theory of analogical access and mapping

Determinants of negative priming

Negative priming from ignored distractors in visual selection: A review

Memory illusions: recalling, recognizing, and recollecting events that never occurred

False recognition in younger and older adults: Exploring the characteristics of illusory memories

Perceptual learning

The influence of irrelevant location information on performance: A review of the Simon and spatial Stroop effects

On the reality of cognitive illusions

Stroop performance in healthy younger and older adults and in individuals with dementia of the Alzheimer's type

High-level scene perception

Failure to detect changes to people during a realworld interaction

\section{$J E P: L M C$}

1996

27.08

Trends Cog Sci

1997

26.83

Psych Rev

1996

26.08

$\operatorname{Cog}$

1995

25.93

$\operatorname{Cog}$

1998

25.45

Psych Rev

1997

25.33

$J E P: H P P$

1995

25.21

Psych Rev

1995

23.43

Perc \& Psychophys

1995

23.36

$B B S$

1999

22.70

Ann Rev Psych

1996

22.38

Psych Rev

1998

22.09

$B B S$

1997

21.92

Ann Rev Psych

1997

21.83

Psych Rev

1999

21.60

Amer Psych

1997

20.83

$P B \& R$

1996

20.77

$B B S$

1999

Psych Bull

1998

19.90

Mem \& $\mathrm{Cog}$

1996

19.55

Vis Cog

1999

19.54

19.20

Trends $\operatorname{Cog} \mathrm{Sci}$

1999

18.70

JEP:Gen

1996

18.69

$J M L$

1999

18.60

J Exp Child Psych

1997

18.42

$P B \& R$

1997

18.25

Psych Rev

1997

18.17

Psych Bull

1995

18.14

PB\&R

1995

18.14

$J M L$

1996

17.85

$\mathrm{Mem} \& \mathrm{Cog}$

1997

17.83

Ann Rev Psych

1998

17.82

$P B \& R$

1995

17.79

Psych Rev

1996

17.69

JEP:HPP

1996

17.62

Ann Rev Psych

1999

17.30

PB\&R

1998 
Gilchrist, A; Kossyfidis, C;

Bonato, F; Agostini, T;

Cataliotti, J; Li, XJ; Spehar, B

Annan, V; Economou, E

Cosmides, L; Tooby, J

Nosofsky, RM; Palmeri, TJ

Simons, DJ; Chabris, CF

McRae, K; Desa, VR;

Seidenberg, MS

Anderson, MC; Spellman, BA

Verhaeghen, P; Salthouse, TA

Klein, RM; Maclnnes, WJ

Goldinger, SD

Treiman, R; Mullennix, J;

Bijeljac-Babic, R; Richmondwelty, ED

Ratcliff, R; Van Zandt, T;

McKoon, G

\section{0-2004}

Coltheart, M; Rastle, K; Perry, C; Langdon, R; Ziegler, J

Yonelinas, AP

Cowan, N

Baddeley, A

Conway, MA; Pleydell-Pearce,

Kahneman, D

Klein, RM

Monsell, S

Hommel, B; Musseler, J;

Aschersleben, G; Prinz, W

Rensink, RA

Anderson, JR; Bothell, D; Byrne,

MD; Douglass, S; Lebiere, C;

Qin, YL

O'Regan, JK; Noe, A

Stanovich, KE; West, RF

Glenberg, AM; Kaschak, MP

Kane, MJ; Engle, RW

Kane, MJ; Hambrick, DZ

Tuholski, SW; Wilhelm, O;

Payne, TW; Engle, RW

Rubinstein, JS; Meyer, DE; Evans, JE

Usher, M; Mcclelland, JL

Engle, RW

Scholl, BJ

Di Lollo, V; Enns, JT; Rensink, RA
An anchoring theory of lightness perception

Psych Rev

1999

16.80

Are humans good intuitive statisticians after all?

$\operatorname{Cog}$

1996

Rethinking some conclusions from the literature on

judgment under uncertainty

An exemplar-based random walk model of speeded classification

Gorillas in our midst: sustained inattentional blindness for dynamic events

On the nature and scope of featural representations of word meaning

On the status of inhibitory mechanisms in cognition: Memory retrieval as a model case

Meta-analyses of age-cognition relations in adulthood: Estimates of linear and nonlinear age effects and structural models

Inhibition of return is a foraging facilitator in visual search

Echoes of echoes? An episodic theory of lexical access

The special role of rimes in the description, use, and acquisition of English orthography

Connectionist and diffusion models of reaction time

$\begin{array}{lcc}\text { Psych Rev } & 1997 & 16.75 \\ \text { Perc } & 1999 & 16.60 \\ \text { JEP:Gen } & 1997 & 16.58 \\ \text { Psych Rev } & 1995 & 16.50 \\ \text { Psych Bull } & 1997 & 16.50 \\ & & \\ \text { Psych Sci } & 1999 & 16.40 \\ \text { Psych Rev } & 1998 & 16.36 \\ \text { JEP:Gen } & 1995 & 16.29 \\ & & \\ \text { Psych Rev } & 1999 & 16.00\end{array}$

DRC: A dual route cascaded model of visual word recognition and reading aloud

The nature of recollection and familiarity: A review of 30 years of research

The magical number 4 in short-term memory: A reconsideration of mental storage capacity

The episodic buffer: A new component of working memory?

The construction of autobiographical memories in the self-memory system

A perspective on judgment and choice: Mapping bounded rationality

Inhibition of return

Task switching

The theory of event coding (TEC): A framework for perception and action planning

Change detection

An integrated theory of the mind

A sensorimotor account of vision and visual consciousness

Individual differences in reasoning: Implications for the rationality debate?

Grounding language in action

Working-memory capacity and the control of attention: The contributions of goal neglect, response competition, and task set to Stroop interference

The generality of working memory capacity: A latentvariable approach to verbal and visuospatial memory span and reasoning

Executive control of cognitive processes in task switching

The time course of perceptual choice: The leaky, competing accumulator model

Working memory capacity as executive attention

Objects and attention: The state of the art

Competition for consciousness among

visual events: The psychophysics

of reentrant visual processes

\begin{tabular}{|c|c|c|}
\hline Psych Rev & 2001 & 72.75 \\
\hline$J M L$ & 2002 & 70.86 \\
\hline$B B S$ & 2001 & 61.38 \\
\hline Trends Cog Sci & 2000 & 60.67 \\
\hline Psych Rev & 2000 & 48.33 \\
\hline Amer Psych & 2003 & 42.17 \\
\hline Trends $\operatorname{Cog} S c i$ & 2000 & 41.89 \\
\hline Trends Cog Sci & 2003 & 40.00 \\
\hline$B B S$ & 2001 & 39.50 \\
\hline Ann Rev Psych & 2002 & 30.86 \\
\hline Psych Rev & 2004 & 29.80 \\
\hline$B B S$ & 2001 & 29.75 \\
\hline$B B S$ & 2000 & 28.67 \\
\hline$P B \& R$ & 2002 & 25.86 \\
\hline JEP:Gen & 2003 & 25.67 \\
\hline JEP:Gen & 2004 & 25.60 \\
\hline$J E P: H P P$ & 2001 & 25.00 \\
\hline Psych Rev & 2001 & 24.50 \\
\hline Curr Dir Psych Sci & 2002 & 24.43 \\
\hline $\operatorname{Cog}$ & 2001 & 22.50 \\
\hline JEP:Gen & 2000 & 22.22 \\
\hline
\end{tabular}


Friedman, NP; Miyake, A

Tipper, SP

Brown, GDA; Preece, T; Hulme, C

Awh, E; Jonides, J

Seymour, PHK; Aro, M; Erskine, JM; Wimmer, H; Leybaert, J; Elbro, C; Lyytinen, H; Gombert, JE; Le Normand, MT; Schneider, W; Porpodas, C; Ragnarsdottir, H; Tressoldi, P; Vio, C; De Groot, A; Licht, R; Iannessen, FE; Castro, SL; Cary, L; Defior, S; Martos, F; Olofsson, A

Waszak, F; Hommel, B; Allport, A

Mayr, U; Keele, SW

Vogel, EK; Woodman, GF; Luck, SJ

Meiran, N; Chorev, Z; Sapir, A

Kersten, D; Mamassian, P;

Yuille, A

Pickering, MJ; Garrod, S

Castles, A; Coltheart, M

Lavie, N; Hirst, A; de Fockert, JW; Viding, E

Indefrey, P; Levelt, WJM

Barsalou, LW; Simmons, WK;

Barbey, AK; Wilson, CD.

Simons, DJ

Nelson, KD; Fivush, R

Kane, MJ; Bleckley, MK; Conway, ARA; Engle, RW Logan, GD; Gordon, RD

Ernst, MO; Bulthoff, HH

Alvarez, GA; Cavanagh, P

Reichle, ED; Rayner, K

Pollatsek, A

Leder, H; Bruce, V

Logan, GD; Bundesen, C

Harm, MW; Seidenberg, MS

Park, DC; Lautenschlager, G; Hedden, T; Davidson, NS; Smith, AD; Smith, PK

Ratcliff, R; Smith, PL

Conway, ARA; Cowan, N; Bunting, MF; Therriault, DJ; Minkoff, SRB

Ehri, LC; Nunes, SR; Willows, DM; Schuster, BV; YaghoubZadeh, Z; Shanahan, T
The relations among inhibition and interference control functions: A latent-variable analysis

Does negative priming reflect inhibitory mechanisms? A review and integration of conflicting views

Oscillator-based memory for serial order

Overlapping mechanisms of attention and spatial working memory

Foundation literacy acquisition in European orthographies

$\begin{array}{lcc}\text { JEP:Gen } & 2004 & 22.00 \\ \text { QJEP } & 2001 & 21.63 \\ & & \\ \text { Psych Rev } & 2000 & 21.56 \\ \text { Trends Cog Sci } & 2001 & 21.25 \\ \text { Brit J Psych } & 2003 & 21.17\end{array}$

Task-switching and long-term priming:

Cog Psych

2003

21.17

bindings in task-shift costs

Changing internal constraints on action: The role of backward inhibition

Storage of features, conjunctions, and objects in visual working memory

Component processes in task switching

Object perception as Bayesian inference

Toward a mechanistic psychology of dialogue

Is there a causal link from phonological awareness to success in

learning to read?

Load theory of selective attention and cognitive control

The spatial and temporal signatures of word production components

Grounding conceptual knowledge in modalityspecific systems

Current approaches to change blindness

The emergence of autobiographical memory: A social cultural developmental theory

A controlled-attention view of working-memory capacity

Executive control of visual attention in dual-task situations

Merging the senses into a robust percept

The capacity of visual short-term memory is set both by visual information load and by number of objects

The E-Z Reader model of eye-movement control in reading: Comparisons to other models

When inverted faces are recognized: The role of configural information in face recognition

Clever homunculus: Is there an endogenous act of control in the explicit task-cuing procedure?

Computing the meanings of words in reading: Cooperative division of labor between visual and phonological processes

Models of visuospatial and verbal memory across the adult life span

A comparison of sequential sampling models for twochoice reaction time

A latent variable analysis of working memory capacity, short-term memory capacity, processing speed, and general fluid intelligence

Phonemic awareness instruction helps children learn to read: Evidence from the national reading panel's meta-analysis

\begin{tabular}{|c|c|c|}
\hline JEP:Gen & 2000 & 21.11 \\
\hline$J E P: H P P$ & 2001 & 20.13 \\
\hline Cog Psych & 2000 & 20.00 \\
\hline Ann Rev Psych & 2004 & 20.00 \\
\hline$B B S$ & 2004 & 20.00 \\
\hline $\operatorname{Cog}$ & 2004 & 19.80 \\
\hline JEP:Gen & 2004 & 19.80 \\
\hline $\operatorname{Cog}$ & 2004 & 19.80 \\
\hline Trends Cog Sci & 2003 & 19.67 \\
\hline Vis $\operatorname{Cog}$ & 2000 & 19.44 \\
\hline Psych Rev & 2004 & 19.40 \\
\hline JEP:Gen & 2001 & 19.00 \\
\hline Psych Rev & 2001 & 18.75 \\
\hline Trends Cog Sci & 2004 & 18.60 \\
\hline Psych Sci & 2004 & 18.40 \\
\hline$B B S$ & 2003 & 18.17 \\
\hline QJEP & 2000 & 18.00 \\
\hline JEP:HPP & 2003 & 18.00 \\
\hline Psych Rev & 2004 & 18.00 \\
\hline Psych \& Aging & 2002 & 17.43 \\
\hline Psych Rev & 2004 & 17.40 \\
\hline Int & 2002 & 17.14 \\
\hline Read Res Quart & 2001 & 17.13 \\
\hline
\end{tabular}

Read Res Quart 
Enns, JT; Di Lollo, V

Ahissar, M; Hochstein, S

Johnson-Laird, PN; Byrne, RMJ

Franz, VH; Gegenfurtner, KR; Bulthoff, HH; Fahle, M

Spence, C; Shore, DI; Klein, RM

Miyake, A; Friedman, NP; Rettinger, DA; Shah, P;

Hegarty, M

Wylie, G; Allport, A

Grush, R

Norris, D; Mcqueen, JM; Cutler, A

Roediger, HL; Watson, JM;

McDermott, KB; Gallo, DA

Anderson, MC

Intriligator, J; Cavanagh, $\mathrm{P}$

Schuch, S; Koch, I

Newport, EL; Aslin, RN

Evans, JST

Nosek, BA; Banaji, MR

Mondloch, CJ; Le Grand, R;

Maurer, D

Zevin, JD; Seidenberg, MS

Salthouse, TA; Atkinson, TM; Berish, DE
What's new in visual masking? learning

Conditionals: A theory of meaning, pragmatics, and inference

Grasping visual illusions: No evidence for a dissociation between perception and action Multisensory prior entry

How are visuospatial working memory, executive functioning, and spatial abilities related? A latent-variable analysis

Task switching and the measurement of switch costs

The emulation theory of representation: Motor control, imagery, and perception

Merging information in speech recognition:

Feedback is never necessary

Factors that determine false recall: A multiple regression analysis

Rethinking interference theory: Executive control and the mechanisms of forgetting

The spatial resolution of visual attention

The role of response selection for inhibition of task sets in task shifting

Learning at a distance: I.

Statistical learning of non-adjacent dependencies

In two minds: dual-process accounts of reasoning

The go/no-go association task

Configural face processing develops more slowly than featural face processing

Age of acquisition effects in word reading and other tasks

Executive functioning as a potential mediator of agerelated cognitive decline in normal adults.

\begin{tabular}{|c|c|c|}
\hline Trends Cog Sci & 2000 & 17.11 \\
\hline Trends Cog Sci & 2004 & 16.80 \\
\hline Psych Rev & 2002 & 16.57 \\
\hline Psych Sci & 2000 & 16.56 \\
\hline JEP:Gen & 2001 & 16.38 \\
\hline JEP:Gen & 2001 & 16.25 \\
\hline Psych Res & 2000 & 16.22 \\
\hline$B B S$ & 2004 & 16.20 \\
\hline$B B S$ & 2000 & 16.11 \\
\hline$P B \& R$ & 2001 & 16.00 \\
\hline$J M L$ & 2003 & 16.00 \\
\hline Cog Psych & 2001 & 15.75 \\
\hline$J E P: H P P$ & 2003 & 15.67 \\
\hline Cog Psych & 2004 & 15.60 \\
\hline Trends Cog Sci & 2003 & 15.50 \\
\hline Soc Cog & 2001 & 15.25 \\
\hline Perc & 2002 & 15.00 \\
\hline$J M L$ & 2002 & 14.86 \\
\hline JEP:Gen & 2003 & 14.83 \\
\hline
\end{tabular}

${ }^{\mathrm{a}}$ The legend for the journal abbreviations can be found in Table 1.

\section{Appendix B}

Procedure for our supplemental search using Harzing's Publish or Perish

We supplemented our database by conducting additional searches using Harzing's Publish or Perish (HPOP) software to find additional articles that would qualify for entry on our top-500 list. Because it would be impractical to do searches for all cognitive psychologists, we restricted our search to the 78 authors whose articles are included in our Table 3. We typed the name of each author into the "Author impact" tab and proceeded to select any article, book, or book chapter whose mean cites per year exceeded by at least $20 \%$ the value for the article with the lowest number of mean cites per year in that article, book, or chapter's corresponding era bin (see the last column of Table 2). Because we did not have data for all available issues of the 56 journals that we surveyed through WoS-usually the earlier issues were the ones not included-we also conducted searches by journal using the "Journal impact" tab to find any highly cited articles that appeared in these missing issues. We also conducted such a search for the two journals (Journal of Research in Reading and Thinking $\&$ Reasoning) that we had omitted because there were only 2 years of data for each of them. Articles that did not meet our selection criteria, stated in the "Method" section, were excluded. To save space, we present below only the results from the additional journal searches.

Because the mean-cites-per-year data from HPOP were almost always greater than those obtained from WoS, whenever possible, we returned to WoS to compute the meancites-per-year data for journal articles. (We were able to obtain WoS data for almost all of the additional articles.) For the books, book chapters, and articles for which WoS data were not available, the mean-cites-per-year and totalcitations data are based on those provided by HPOP at the time that the searches were made (between January 5 and 15, 2012). A potential limitation of the supplemental data for uncovering publications that would have made our top500 list is that we limited our search to the 78 authors who had three or more publications in our top-500 list. However, we believe that this is not a major limitation, because these eminent authors are the most likely to have other highly 
cited publications that we might have missed in our WoS search.

\begin{tabular}{|c|c|c|c|c|c|}
\hline Author(s) & Title & Journal $^{\mathrm{a}}$ & Year & Cites/Year & Total Citations \\
\hline Baddeley, AD; Hitch, GJL & Working memory & Psych Learn \& Motiv & 1974 & 145.76 & 5,101 \\
\hline Atkinson, RC; Shiffrin, RM & $\begin{array}{l}\text { Human memory: A proposed } \\
\text { system and its control processes }\end{array}$ & Psych Learn \& Motiv & 1968 & 99.07 & 4,062 \\
\hline Hasher, L; Zachs, RT & $\begin{array}{l}\text { Working memory, comprehension, } \\
\text { and aging: A review and a new view }\end{array}$ & Psych Learn \& Motiv & 1988 & 72.46 & 1,522 \\
\hline Sweller, J & $\begin{array}{l}\text { Cognitive load theory, learning difficulty, } \\
\text { and instructional design }\end{array}$ & Learn \& Instr & 1994 & 47.22 & 708 \\
\hline Oatley, J; Johnson-Laird, PN & Towards a cognitive theory of emotions & $\operatorname{Cog} \&$ Emot & 1987 & 40.8 & 898 \\
\hline Nelson, TO; Narens, L & $\begin{array}{l}\text { Metamemory: A theoretical framework } \\
\text { and new findings }\end{array}$ & Psych Learn \& Motiv & 1990 & 30.09 & 572 \\
\hline Ehri, LC & $\begin{array}{l}\text { Phases of development in learning to } \\
\text { read words by sight }\end{array}$ & $J$ Res Reading & 1995 & 26.83 & 376 \\
\hline Garrett, MF & The analysis of sentence production & Psych Learn \& Motiv & 1975 & 21.3 & 724 \\
\hline Leventhal, H; Scherer, KR & $\begin{array}{l}\text { The relationship of emotion to cognition: } \\
\text { A functional approach to a semantic } \\
\text { controversy }\end{array}$ & $\operatorname{Cog} \&$ Emot & 1987 & 21 & 462 \\
\hline Mandler, G & Organization and memory & Psych Learn \& Motiv & 1967 & 15.2 & 638 \\
\hline Bousfield, W & $\begin{array}{l}\text { The occurrence of clustering in the } \\
\text { recall of randomly arranged associates }\end{array}$ & $J$ Gen Psych & 1953 & 13.95 & 781 \\
\hline Dyer, FN & $\begin{array}{l}\text { The Stroop phenomenon and its use in } \\
\text { the study of perceptual, cognitive, } \\
\text { and response processes }\end{array}$ & $M e m \& C o g$ & 1973 & 10.44 & 375 \\
\hline Bower, GH & A multicomponent theory of the memory trace & Psych Learn \& Motiv & 1967 & 9.02 & 378 \\
\hline
\end{tabular}

${ }^{\mathrm{a}} J$ Res Reading $=$ Journal of Research in Reading; Learn \& Instr = Learning \& Instruction; for all other journal abbreviations, see Table 1.

\section{References}

Adair, J. G., \& Vohra, N. (2003). The explosion of knowledge, references, and citations: Psychology's unique response to a crisis. American Psychologist, 58, 15-23. doi:10.1037/0003-066X.58.1.15

Althouse, B. M., West, J. D., Bergstrom, C. T., \& Bergstrom, T. (2009). Differences in impact factor across fields and over time. Journal of the American Society for Information Science and Technology, 60, 27-34.

Battig, W. F., \& Montague, W. E. (1969). Category norms of verbal items in 56 categories: A replication and extension of the Connecticut category norms. Journal of Experimental Psychology, 80 (3, Pt. 2), 1-46. doi:10.1037/h0027577

Clark, H. H. (1973). The language-as-fixed-effect fallacy: A critique of language statistics in psychological research. Journal of Verbal Learning and Verbal Behavior, 12, 335-359. doi:10.1016/S00225371(73)80014-3

Crowder, R. G. (1982). The demise of short-term memory. Acta Psychologica, 50, 291-323. doi:10.1016/0001-6918(82)90044-0

de Solla Price, D. (1986). Little science, big science . . . and beyond. New York, NY: Columbia University Press.

Egghe, L. (2006). Theory and practise of the $g$-index. Scientometrics, 69, 131-152. doi:10.1007/s11192-006-0144-7

Egly, R., Driver, J., \& Rafal, R. D. (1994). Shifting visual attention between objects and locations: Evidence from normal and parietal lesion subjects. Journal of Experimental Psychology: General, 123, 161-177. doi:10.1037/0096-3445.123.2.161

Endler, N. S. (1977). Research productivity and scholarly impact of Canadian psychology departments. Canadian Psychological Review, 18, 152-168. doi:10.1037/h0081428

Garfield, E. (1972). Citation analysis as a tool in journal evaluation. Science, 178, 471-479. doi:10.1126/science.178.4060.471
Garfield, E., \& Welljams-Dorof, A. (1992). Of Nobel class: A citation perspective on high impact research authors. Theoretical Medicine and Bioethics, 13, 117-135. doi:10.1007/ BF02163625

Gentner, D. (1983). Structure-mapping: A theoretical framework for analogy. Cognitive Science, 7, 155-170. doi:10.1207/s15516709 $\operatorname{cog} 0702 \_3$

Harzing, A. W. (2007). Publish or perish (Version 3.2) [Software]. Available from www.harzing.com/pop.htm

Harzing, A. W. (2010). The publish or perish book: Your guide to effective and responsible citation analysis. Melbourne, Australia: Tarma Software Research Pty Ltd.

Hegarty, P., \& Walton, Z. (2012). The consequences of predicting scientific impact in psychology using journal impact factors. Perspectives on Psychological Science, 7, 72-78. doi:10.1177/ 1745691611429356

Hirsch, J. E. (2005). An index to quantify an individual's scientific research output. Proceedings of the National Academy of Sciences, 102, 16569-16572. doi:10.1073/pnas.0507655102

Krampen, G., Becker, R., Wahner, U., \& Montada, L. (2007). On the validity of citation counting in science evaluation: Content analyses of references and citations in psychological publications. Scientometrics, 71, 191-202. doi:10.1007/ s11192-007-1659-2

London School of Economics Public Policy Group. (2011). Maximizing the impacts of your research: A handbook for social scientists. Retrieved July 17, 2011, from http://nphf.nl/footage/fm/File/pdf/LSE_Impact_Handbook_April_2011.pdf

Luck, S. J., \& Vogel, E. K. (1997). The capacity of visual working memory for features and conjunctions. Nature, 390, 279-281. doi: $10.1038 / 36846$

Myers, C. R. (1970). Journal citations and scientific eminence in contemporary psychology. American Psychologist, 25, 10411048. doi:10.1037/h0030149 
Neisser, U. (1967). Cognitive psychology. New York, NY: Appleton. Nosek, B. A., Graham, J., Lindner, N. M., Kesebir, S., Hawkins, C. B., Hahn, C., . . . Tenney, E. R. (2010). Cumulative and career-stage citation impact of social-personality psychology programs and their members. Personality and Social Psychology Bulletin, 36, 1283-1300. doi:10.1177/0146167210378111

"Not-so-deep impact" [Editorial]. (2005). Nature, 435, 1003-1004. doi:10.1038/4351003b

Pelli, D. G. (1997). The VideoToolbox software for visual psychophysics: Transforming numbers into movies. Spatial Vision, 10, 437442. doi:10.1163/156856897X00366

Ratcliff, R. (1979). Group reaction time distributions and an analysis of distribution statistics. Psychological Bulletin, 86, 446-461. doi:10.1037/0033-2909.86.3.446

Roediger, H. L., III. (2004). Great dissertations: Mark I. APS Observer. Retrieved from www.psychologicalscience.org/ index.php/uncategorized/great-dissertations-mark-i.html

Roediger, H. L., III. (2006). The h index in science: A new measure of scholarly contribution. APS Observer. Retrieved from www. psychologicalscience.org/observer/getArticle.cf mid=1971

Rushton, R. J. (1984). Evaluating research eminence in psychology: The construct validity of citation counts. Bulletin of the British Psychological Society, 37, 33-36.
Shepard, R. N., \& Metzler, J. (1971). Mental rotation of threedimensional objects. Science, 171, 701-703. doi:10.1126/ science.171.3972.701

Standing, L. G. (2009). Public recognition of major works in psychology: Rise and fall over time. Social Behavior and Personality, 37, $145-148$.

Thomson Reuters. (n.d.-a). Introducing the impact factor. Retrieved July, 16, 2011 from http://thomsonreuters.com/products_services/ science/academic/impact_factor/

Thomson Reuters. (n.d.-b). Journal self-citation in the journal citation reports. Retrieved July, 20, 2011 from http:// thomsonreuters.com/products_services/science/free/essays/ journal_self_citation_jcr/

Thomson Reuters. (n.d.-c). Social sciences citation index. Retrieved July, 16, 2011, from http://thomsonreuters. com/products_services/science/science_products/a-z/ social_sciences_citation_index/

White, M. J. (1983). Prominent publications in cognitive psychology. Memory \& Cognition, 11, 423-427. doi:10.3758/BF03202459

Wilhite, A. W., \& Fong, E. A. (2012). Coercive citation in academic publishing. Science, 335, 542-543. doi:10.1126/science.1212540

Zhang, C.-T. (2009). The e-index, complementing the h-index for excess citations. PLoS ONE, 4, e5429. doi:10.1371/journal.pone.0005429 